\title{
The Stochastic Effect of Nanoparticles Inter-Separation Distance on Membrane Wettability During Oil/Water Separation
}

\author{
P. B. Sob ${ }^{1}$, A. A. Alugongo ${ }^{2}$ and T. B. Tengen ${ }^{3}$ \\ ${ }^{1,2}$ Departmentof Mechanical Engineering, Faculty of Engineering and Technology, Vaal University of Technology, \\ Vanderbijlpark 1900, Private Bag X021, South Africa. \\ ${ }^{3}$ Department of Industrial Engineering and Operations Management, Faculty of Engineering and Technology, \\ Vaal University of Technology, Vanderbijlpark 1900, Private Bag X021, South Africa.
}

${ }^{1}$ ORCID: 0000-0002-1796-7694

\begin{abstract}
Engineers and scientists are faced with a major challenge of developing predictive models of nanoparticles scattering during membrane coating for efficient oil/water separation. Mechanical molecular simulation studies of key parameters or variable for structure/property correlations during nanoparticles coating are analysed on surface energy driven separability in the current study. The tools of stochastic process were used to study the random nature of nanoparticles scattering during membrane coating process using a specific coating technique.
\end{abstract}

The results obtained in this study revealed theoretical facts that were validated experimentally. It was shown that there is a critical nanoparticles scattering that offers optimal membrane wettability. It was also revealed that total membrane coating doesn't leads to optimal nanoparticle scattering during coating. It was also observed that as nanoparticles inter-separation distances decreased, membrane wettability increased. Clusters were also observed on the membrane surface during high and low pressure coating which impacted wettability. The cluster negatively impacted orientation of nanoparticles and wettability. It was shown that there is an optimal nanoparticles inter-separation distance which gave optimal membrane wettability after $3^{\text {rd }} \mathrm{HP}$ round of coating. Different orientation of nanoparticles, size, shape, spatial distribution and morphology were also observed to impact membrane wettability. Clusters were also observed on the membrane and more clusters were observed in LP coating when compared with HP coating. These clusters greatly impacted membrane wettability negatively. Good correlation was observed from the SEM images, EDS and Descriptive statistics of the amount of elements in the surface layer formed after different coating rounds.

Keywords: Nanoparticle, inter-separation distance, coating, surface tension and surface energy.

\section{Nomenclature:}

$\begin{array}{ll}\text { TEM } & \text { is transmission electron microscope } \\ \mathrm{SEM} & \text { is scanning electron microscope } \\ \mathrm{HP} & \text { is high pressure coating } \\ \mathrm{LP} & \text { is low pressure coating } \\ \mathrm{EDS} & \text { is energy dispersion spectroscopy } \\ \mathrm{O} & \text { is oxygen } \\ \mathrm{Na} & \text { is sodium } \\ \mathrm{Mg} & \text { is magnesium } \\ \mathrm{Al} & \text { is aluminium } \\ \mathrm{Si} & \text { is silicon } \\ \mathrm{Ca} & \text { is calcium } \\ \mathrm{F} & \text { is fluorine } \\ \mathrm{S} & \text { is sulphur }\end{array}$

\section{MATERIALS AND METHODS}

\subsection{Introduction}

There is no standard technique of nanoparticle coating when using spray guns (1-4). Sometimes, by using the spray gun, an appropriate coating thickness which is homogeneous with proper nanoparticle inter-separated distances and films are created (1-4). It has been reported that the jet impact momentum of droplets during coating depends on the coating pressure (1-5). There is high and low impact momentum when using the jet gun (1-5). In high pressure coating the droplet penetrates into pits and scratches thus 
enhancing the wettability surface (1-4). The coating droplet depositions are also affected by air flow field and also by the uncontrolled gun-to-target distance due to different operator skill level (1-2). This has led to the current problem of coating deficiencies, thereby limiting the efficient transfer (of what?????), which influencing the film thickness distribution and nanoparticle scattering (1-6). There are other problems during coating such as strong shoreline winds which affect membrane coating process and surface properties (1-5). It was reported by (1-6) that to understand coating processing behaviour, it is important to carry out a detail research investigations on nanoparticle scattering, nano-particle spatial distribution, morphology of nano-particles, nano-particle sizes, nano-particle shape and nano-particle thickness during high pressure (HP) and low pressure (LP) coatings. Little research on particle scattering has been carried out by Plesniak et al. [2] and Ye et al [1] on wind effect during coating. Plesniak et al. [2] focused on spray transfer efficiency (TE) and the effect on spray parameters during booth coating. Parameters such as mass flow rate, gun-totarget distance and gun-to-target angle during coating were investigated (1-6 \& 8-25). Few research works gave clear correlation between theoretical and experimental data (1-6 \& 8-24).

Experimental and numerical research investigation on different atomizers such as high-speed rotary bells having electrostatic support system, pneumatic application using coaxial jet type atomizers, as well as powder coating (1) were carried out at Fraunhofer Institute for Manufacturing Engineering and Automation (IPA) [1 \& 4-6]. Parameters such as film thickness distribution and efficiency under varying conditions, and varying boundary conditions for conventional materials were analysed. The research studies presented great contribution to experimental results of spray coating using flat jet gun (1). The experimental results also gave the necessary boundary conditions for the relevant trajectory during coating. Different surface roughness were reported to impact membrane wettability due to varying spatial distribution, varying sizes, varying shape, varying morphology, varying orientation and varying inter-separation distances (1-5 \& 8-25)). Computed film thickness distribution and transfer of efficiency during the coating process were compared with experimental results (1). Parametric studies were done during numerical simulations and the effects of side winds and gun-to-target distances on film thickness were analysed (1). It was observed that materials coating are greatly affected by winds during the coating process. Therefore the high pressure (HP) coating and low pressure (LP) coating have different impact on spatial distribution, sizes, shape, morphology, orientation and inter-separation distances (1-5 \& 8-25). These have different impact of membrane surface roughness and smoothness which impact surface energy and surface tension driven separability. The lotus effect, which is a traditional model on surface wettability, justified that smooth surface enhanced wettability and that rough surface decreased wettability (1-5 \& 8-25).

Most of the existing models used in wettability only takes into consideration the impact of the external parameters during coating such as diameter of the jet spray, coating pressure, impact momentum, coating distances and angle of coating to study wettability (1-6 \& 8-25). These parameters are insufficient since there are several ignored parameters during coating. This has resulted to the fabrication of membrane surface that are inefficient during oil and water separation (125). Therefore to design a membrane surface that is more efficient during oil/water separation, all ignored parameters must be taken into consideration. These parameters are the random natures of nanoparticle scattering, nano-particle spatial distribution, morphology of nano-particles, nanoparticle sizes, nano-particle shape (1-25). In this current study more physical parameters that impact membrane wettability and inter-separation distances are taken in to consideration. This has led to the design of a new membrane surface with improved efficiency of oil/water separation.

2.2. Glass hydrophobic nanoparticles and spray gun were purchased for the experiment. The glass materials were washed to remove foreign impurities such as dirt that could have prevented proper blending of nanoparticle on the glass surface during coating (1-6 \& 8-25). This was done with the help of a distilled water and pre-clean water. The washed glass membranes were allowed to dry for 24 hours under room temperature. The coating process was done using HP coating and LP coating. The jet spray gun used for coating was kept $5 \mathrm{~cm}$ away from the membrane surface at an angle perpendicular (90 degree). Before coating took place, uncoated sample (membrane material i.e the glass material and nano4glass) was taken for for microscopy analysis. The first, second and third rounds of coatings were done at LP and samples after each round were removed for microscopy analysis. Similarly first, second and third rounds of coatings were done at HP and (coated glass material) were removed for microscopy analysis. The second and third rounds of coating were done in less than three minutes to prevent the membrane surface from becoming hydrophobic to the coated materials which will repel the second and third coating rounds. The glass membranes without coating (control glass) were characterized using ESD to detect their elements. The following elements were observed as shown in Fig. 1(b), Oxygen (O), $\mathrm{Mg}, \mathrm{Si}$, and $\mathrm{Ca}$. The purchased hydrophobic nanoparticles used for membrane coating were also characterized using EDS and the following element for glass hydrophobic nanoparticles were observed as shown in Fig. 1 (c), O, F, Na, Si, S and Ca. The hydrophobic nanoparticles for glass used in membrane coating were having unique elements of fluorine (F), $\mathrm{Na}$, and $\mathrm{S}$ and the glass control sample were having a unique element of $\mathrm{Mg}$. Since the main 
aim of the current study was to investigate membrane interseparation distances due to nano-particle size, spatial distribution of nanoparticle, morphology of nano-particles, nano-particle shape and nano-particle thickness which impacted inter-separation distances during HP and LP coating. Microscopy analysis was done to analyse the random phenomena of these parameter during HP and LP coating rounds for the establishment of an empirical model of surface tension and surface energy and their impact on wettability.

\subsection{The samples preparation for SEM, TEM and EDS}

2.3.1 The samples were not polished since the surface roughness of the coated hydrophobic nano for glass was the main parameter to be measured. The sample was embedded in epoxy resin blocks and later the thin section to be analysed was prepared. The holders in which the glass sample were placed for microscopy analysis was $25 \mathrm{~mm}$ or (1") diameter round. The glass samples are electrically non-conducting during analysis and a conducting surface coated was applied to provide proper path for the incident electrons to flow to ground during analysis. Normally the coating material is vacuum-evaporated carbon ( 10nm thick), having a minimal influence on X-ray intensities due to its low atomic number as specify for SEM sample so that it does not add unwanted peaks to the X-ray spectrum. To achieve higher resolution during SEM imaging, advanced detectors were used during SEM analysis. These were used to selectively detect the different location as indicated by spectrum 2 to spectrum 8 called site of interest where the lens was able to capture results. This was to ensure accuracy and elementary validation of findings on how particles were distributed on the membrane surface during coating as shown in Fig 1 (e). During the SEM analysis, the detector used was an In-Lens SE detector (Zeiss Supra 40, FE-SEM, Oberkochen, Germany). It must be noted that the In-Lens was only able to pick images in a straight path. Therefore the In-Lens was unable to pick images in curve section of the glass membrane and as such the sections were black in the SEM captured images. The nanoparticles sizes, shape, orientation, morphology and dispersion of lateral dimensions were measured. It should be noted that the STEM detector being placed under the samples was used to capture images in transmission mode in the SEM during experiment. This consists of sample holders which guide the transmitted electrons onto the electron multiplier in the form of a gold plate under the bright field. All the transmitted electrons are collected by the E-T detector. At the same time the screening ring being operated prevented the X-rays being emitted by the sample to reach the EDS detector and therefore it is important to remove the ring before an EDS analysis. More so a TEM grid transmission setup was used and the TSEM detector was able to analysed four samples on the holders and EDS analysis was carried out immediately.

The various images of SEM and EDS configurations were captured for LP and HP. The coating thickness, surface spread, roughness, smoothness, contact angles, interseparation distances, size, morphology, spatial distribution were observed and measured using SEM, image J particle analyser and energy dispersive X-ray spectroscopy. The viscosities of nanoparticle scattering were measured at room temperature using a rheometer (physica MCR301, Anton Paar Gmbh Graz, Austria). The densities of nanoparticles were also measured at room temperature with a densitometer (30 PX, Metler Toledo, Viroflay France). The surface tension were measured with a tensiometer ( $3 \mathrm{~s}$ GBX, Bourg de peage, France) using the wilhelmy plate method. To measure the contact angle drops of water were place on a flat coated membrane surface and the angle were measured with a goniometer (DiGi Drop Fast/60, GBX, Bourg de peage France). The thickness and inter-separation distances during nanoparticle coating depend on the coating velocity and the physical properties (viscosity of scattering of nanoparticle). Due to these factors the thickness and inter-separation distances differs with velocity of nanoparticles coating for HP and LP during TEM and SEM observation. Bulk sample analysis in the SEM showed a conventional E-T detector which collected the SE/BSE electrons during the analysis. The SE electrons may also be collected using a high-resolution InLens SE detector during analysis. It is important to note that the large emission volume of X-rays can be collected by an EDS detector.

In the current study the following EDS detectors were used to analyse a $10 \mathrm{~mm}^{2}$ glass, coated glass and hydrophobic nanoparticles (Thermo Scientific, USA), a $10 \mathrm{~mm}^{2}$, SDD (Bruker, Germany), a $100 \mathrm{~mm}^{2}$, SDD (Thermo Scientific, USA), with an annular $60 \mathrm{~mm}^{2}$ FlatQUAD SDD (Bruker, Germany). The SDD annular is being inserted between the pole shoe and the experimental sample, to give a very large solid angle of the X-rays being emitted by the sample. For the TEM analysis the sample were not etched or polish since the coated nanoparticles was on the surface of the membrane. A standard TEM thin foil $3 \mathrm{~mm}$ in diameter were prepared for analysis by electrolytic twin-jet (at $-30^{\circ} \mathrm{C}, 30 \mathrm{~V}$ ) in Struers Tenupol 2 filled with $6 \%$ solution of perchloric acid in methanol. This observations were all carried out at $200 \mathrm{kV}$ with JEOL JEM 2000FX microscope equipped with an X-ray energy dispersive spectrometer (XEDS) 53 LINK AN 10000 (26). The diameter, length, orientation, angles, morphology, spatial distribution of the coated nanoparticles on the membrane surface was measured as shown in Fig 1 (d). 


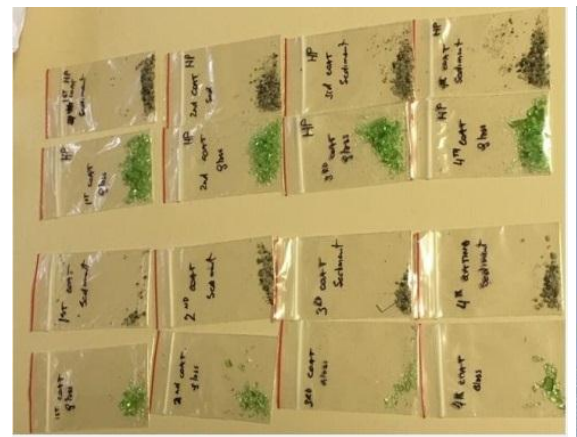

(a)

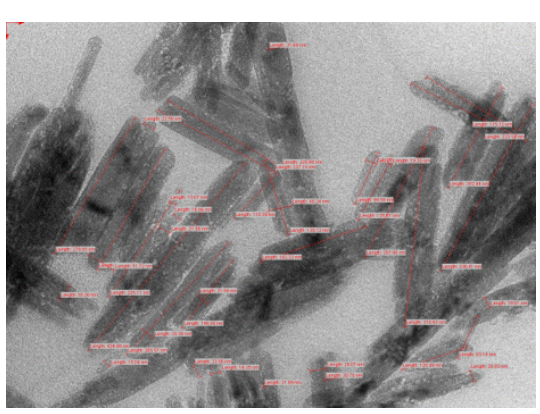

(d)

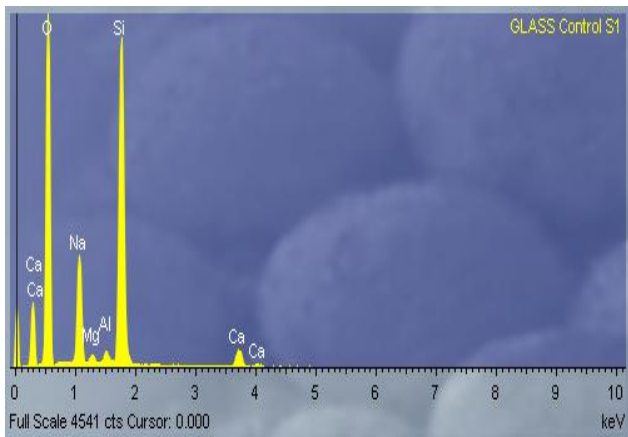

(b)

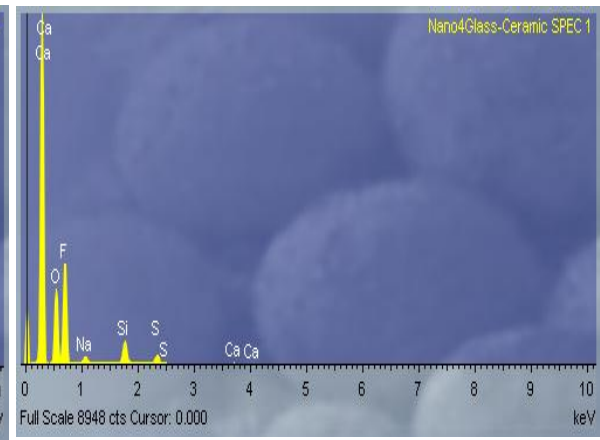

(c)

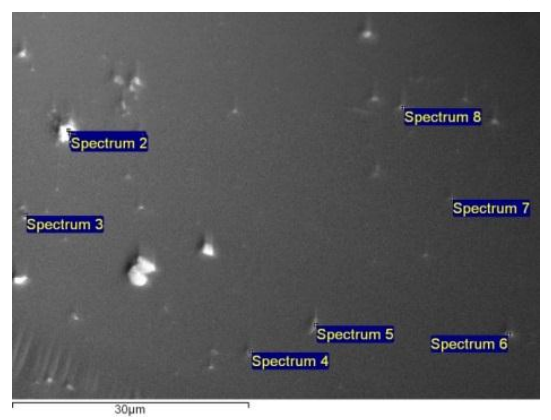

(e)

Figure 1 (a) Glass after hydrophobic nanoparticle coating, (b) control glass material after EDS analysis (c) control hydrophobic for glass material after EDS analysis (d) TEM measurement of length and diameter of control nano hydrophobic glass material used for coating and (e) Spectrum lens location on the samples.

It was important to do a correlation with the EDS, Descriptive statistical analysis and SEM images during LP and HP coating. Before this correlation were done it was important to first analyse the control sample for glass, nano hydrophilic for glass and their descriptive statistical analysis.
Description details

SOB 2Project 1

Project: SOB 2Project 1

Owner: INCA Operator

Site: Site of Interest 1

Sample: GLASS Control

Type: Default

ID: GLASS Control

Table 1: Descriptive statistics of the amount of elements in the surface layer formed in glass control sample ESD setting

\begin{tabular}{|l|l|l|l|l|l|}
\hline SOB 2Project 1 & Project & Owner & Site: & Sample & ID \\
\hline & SOB 2Project 1 & INCA Operator & Site of Interest 1 & GLASS Control & GLASS Control \\
\hline
\end{tabular}

\section{Descriptive statistics}

\begin{tabular}{|l|c|c|c|c|c|c|c|c|}
\hline Spectrum & In stats. & $\mathrm{O}$ & $\mathrm{Na}$ & $\mathrm{Mg}$ & $\mathrm{Al}$ & $\mathrm{Si}$ & $\mathrm{Ca}$ & $\mathrm{Total}$ \\
\hline GLASS Control S1 & Yes & 52.15 & 8.71 & 0.58 & 0.86 & 31.98 & 5.71 & 100.00 \\
\hline GLASS Control S2 & Yes & 59.12 & 8.97 & 0.53 & 0.73 & 25.76 & 4.89 & 100.00 \\
\hline GLASS Control S3 & Yes & 60.00 & 8.88 & 0.67 & 0.86 & 24.92 & 4.67 & 100.00 \\
\hline Mean & & 57.09 & 8.86 & 0.59 & 0.82 & 27.55 & 5.09 & 100.00 \\
\hline Std. deviation & & 4.30 & 0.13 & 0.07 & 0.07 & 3.86 & 0.55 & \\
\hline Max. & & 60.00 & 8.97 & 0.67 & 0.86 & 31.98 & 5.71 & \\
\hline Min. & & 52.15 & 8.71 & 0.53 & 0.73 & 24.92 & 4.67 & \\
\hline
\end{tabular}

All results in weight $\%$ 


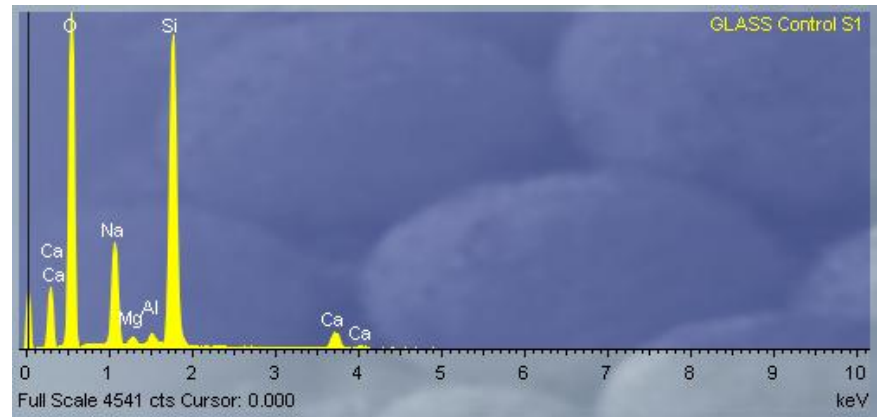

Fig. 2 Correlation between descriptive statistics of amount of elements in surface layer formed in glass control sample and EDS of glass control sample

Both EDS and statistical analysis revealed six elements that were found on the glass control sample. The EDS shows the variation of intensity and kilo electrons volt electrons on a full scale during EDS analysis while the statistical analysis results revealed three site of interest (glass control S1, glass control S2 and glass control S3) which data capturing were obtained. The statistical analysis revealed different mean, standard deviation, max and min which correspond to the varying peak, max spread, and min spread. The observed elements in both EDS and statistical analysis are oxygen $(\mathrm{O})$, sodium $(\mathrm{Na})$, magnesium $(\mathrm{Mg})$, aluminium (Al), silicon ( $\mathrm{Si})$, and calcium (Ca). These elements consist of different atomic number, electronegativity, oxidation states (most common are bold), atomic mass (or most stable mass number), $1^{\text {st }}$ ionisation energy in $\mathrm{KJ} / \mathrm{mol}$, chemical symbol, name and electron configuration. The control glass sample was reported to have very high content of oxygen, followed by sodium, and calcium. Magnesium was reported to have the least content followed by aluminium as shown in table 1 . Good correlation can be seen between the results of EDS and statistical analysis. Oxygen was observed to have the highest peak intensity, followed by $\mathrm{Si}, \mathrm{Na}, \mathrm{Ca}, \mathrm{Al}$ and $\mathrm{Mg}$. It was also important to analyse the composition of hydrophobic nano for glass used in membrane coating. The results for EDS and statistical analysis are discussed in Fig. 3

\section{SOB 2Project 1}

Project: SOB 2Project 1

Owner: INCA Operator

Site: Site of Interest 1

Sample: Nano4Glass

Type: Default

ID: Nano4Glass

Table 2. Descriptive statistics of the amount of elements in the surface layer formed in hydrophobic nano4glass control sample ESD setting

\begin{tabular}{|l|l|l|l|l|l|}
\hline SOB 2Project 1 & Project & Owner & Site: & Sample & ID \\
\hline & SOB 2Project 1 & INCA Operator & Site of Interest 1 & Nano4Glass & Nano4Glass \\
\hline
\end{tabular}

Descriptive statistics

\begin{tabular}{|l|c|c|c|c|c|c|c|c|}
\hline Spectrum & In stats. & O & F & Na & Si & S & Ca & Total \\
\hline Nano4Glass-Ceramic SPEC 1 & Yes & 25.64 & 60.75 & 1.54 & 7.29 & 4.07 & 0.71 & 100.00 \\
\hline Nano4Glass-Ceramic S2 & Yes & 22.52 & 64.30 & 1.52 & 7.71 & 3.41 & 0.55 & 100.00 \\
\hline Nano4Glass-Ceramic S3 & Yes & 28.09 & 59.06 & 1.46 & 6.80 & 4.10 & 0.50 & 100.00 \\
\hline Mean & & 25.41 & 61.37 & 1.51 & 7.27 & 3.86 & 0.58 & 100.00 \\
\hline Std. deviation & & 2.79 & 2.67 & 0.04 & 0.46 & 0.39 & 0.11 & \\
\hline Max. & & 28.09 & 64.30 & 1.54 & 7.71 & 4.10 & 0.71 & \\
\hline Min. & & 22.52 & 59.06 & 1.46 & 6.80 & 3.41 & 0.50 & \\
\hline
\end{tabular}

All results in weight $\%$

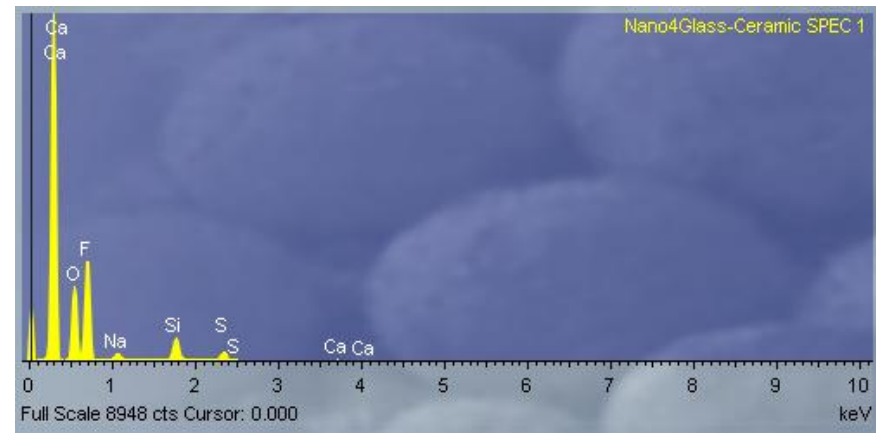

Fig. 3 Correlation between descriptive statistics of amount of elements in surface layer formed in glass control sample and EDS of glass control sample
It is observed from hydrophobic nano4glass control samples that six main elements are found as shown in table 2. These elements are oxygen $(\mathrm{O})$, Fluorine $(\mathrm{F})$, sodium $(\mathrm{Na})$, silicon $(\mathrm{Si})$, Sulfur $(\mathrm{S})$ and calcium $(\mathrm{Ca})$. It is observed as shown in table 2 that there is a new element Fluorine $(\mathrm{F})$ which is not found in glass control samples. Fluorine $(\mathrm{F})$ is the main elements of hydrophobic nanoparticles which created membrane hydrophobicity during oil/water separation process. Therefore $\mathrm{F}$ was the main scattering elements which vary during HP and LP coating rounds. Therefore the morphology, sizes, shape, orientation and spatial distribution of $\mathrm{F}$ was changing during the coating rounds resulting to different inter-separation distances which impacted surface tension and surface energy. It now important analyse the 
International Journal of Engineering Research and Technology. ISSN 0974-3154, Volume 13, Number 5 (2020), pp. $842-866$

(C) International Research Publication House. https://dx.doi.org/10.37624/IJERT/13.5.2020.842-866

different rounds of HP and LP coating since both control samples were already analysed.

SOB 2Project 1

Project: SOB 2Project 1
Owner: INCA Operator

Site: Site of Interest 1

Sample: GLASS 1LP Type: Default

ID: GLASS 1 LP

Table 3: Descriptive statistics of the amount of elements in the surface layer formed in glass $1^{\text {st }}$ round LP after PEO ESD setting

Descriptive statistics

\begin{tabular}{|l|l|l|l|l|l|}
\hline SOB 2Project 1 & Project & Owner & Site: & Sample & ID \\
& SOB 2Project 1 & INCA Operator & Site of Interest 1 & GLASS 1LP Type & GLASS 1 LP \\
\hline
\end{tabular}

\begin{tabular}{|l|c|c|c|c|c|c|c|c|c|c|}
\hline Spectrum & In stats. & $\mathrm{O}$ & $\mathrm{F}$ & $\mathrm{Na}$ & $\mathrm{Mg}$ & $\mathrm{Al}$ & $\mathrm{Si}$ & $\mathrm{S}$ & $\mathrm{Ca}$ & $\mathrm{Total}$ \\
\hline GLASS 1- S1 & Yes & 53.56 & 4.54 & 8.50 & 0.64 & 0.79 & 26.26 & 0.50 & 5.20 & $\begin{array}{c}100.0 \\
0\end{array}$ \\
\hline GLASS 1-S2 & Yes & 48.60 & 5.06 & 8.40 & 0.81 & 0.80 & 29.19 & 1.16 & 5.98 & $\begin{array}{c}100.0 \\
0\end{array}$ \\
\hline GLASS 1-S3 & Yes & 53.98 & 1.83 & 8.85 & 0.57 & 0.78 & 28.26 & 0.27 & 5.46 & $\begin{array}{c}100.0 \\
0\end{array}$ \\
\hline Mean & & 52.05 & 3.81 & 8.58 & 0.68 & 0.79 & 27.91 & 0.64 & 5.54 & 100.00 \\
\hline Std. deviation & & 2.99 & 1.74 & 0.24 & 0.13 & 0.01 & 1.50 & 0.46 & 0.39 & \\
\hline Max. & & 53.98 & 5.06 & 8.85 & 0.81 & 0.80 & 29.19 & 1.16 & 5.98 & \\
\hline Min. & & 48.60 & 1.83 & 8.40 & 0.57 & 0.78 & 26.26 & 0.27 & 5.20 & \\
\hline
\end{tabular}

All results in weight $\%$

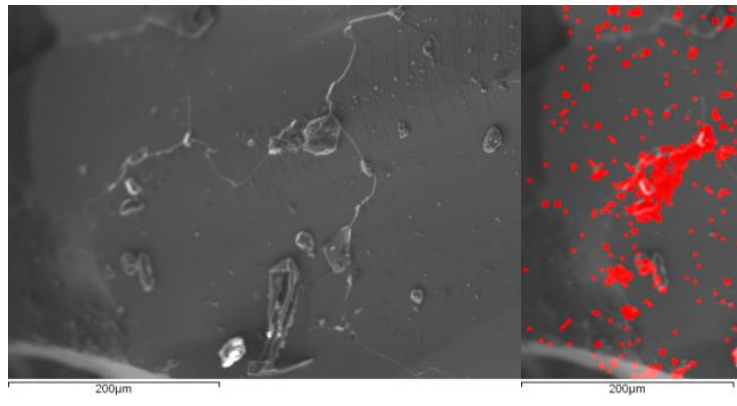

(b)

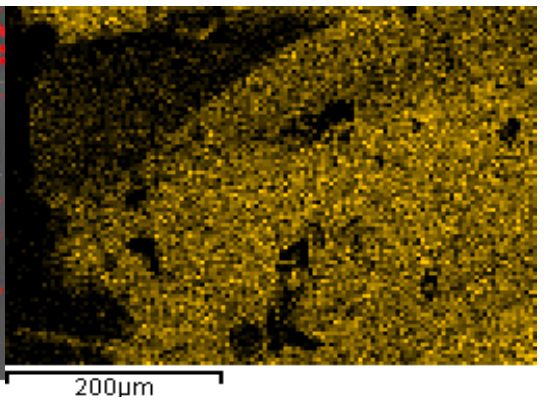

(c)

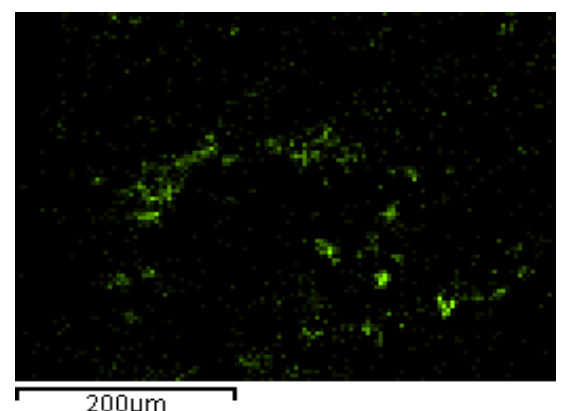

(d)

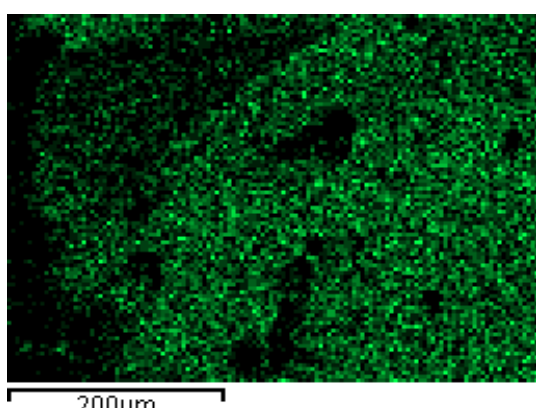

(e )

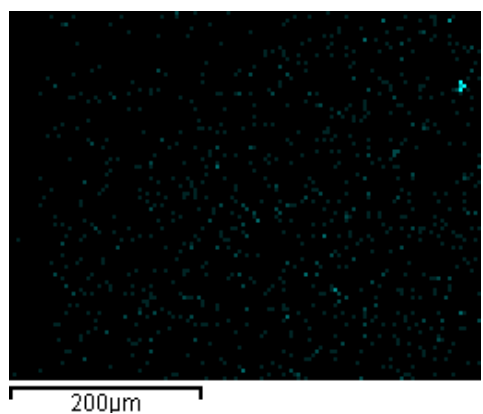

(f) 


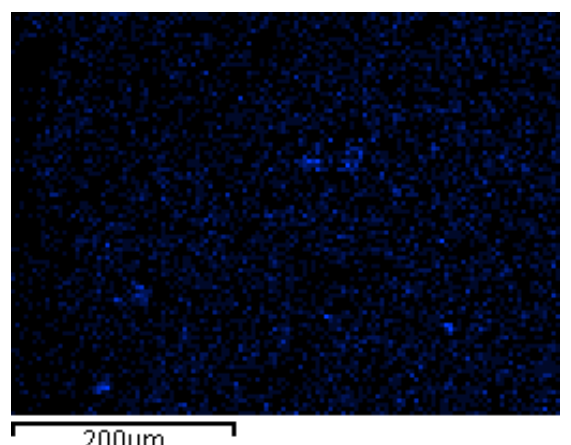

(g)

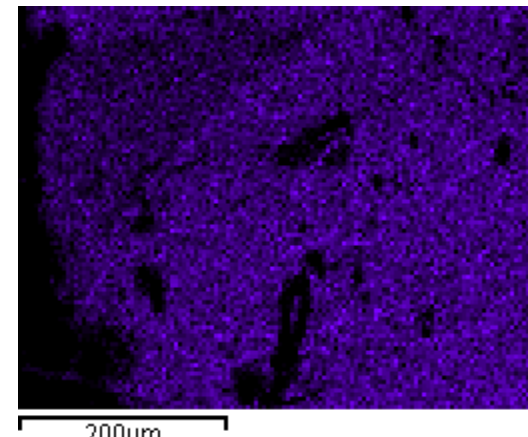

(h)

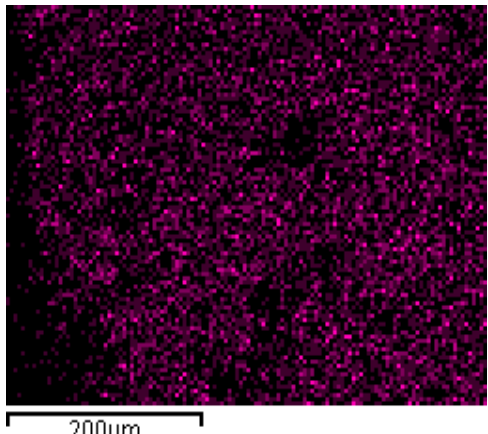

(i)

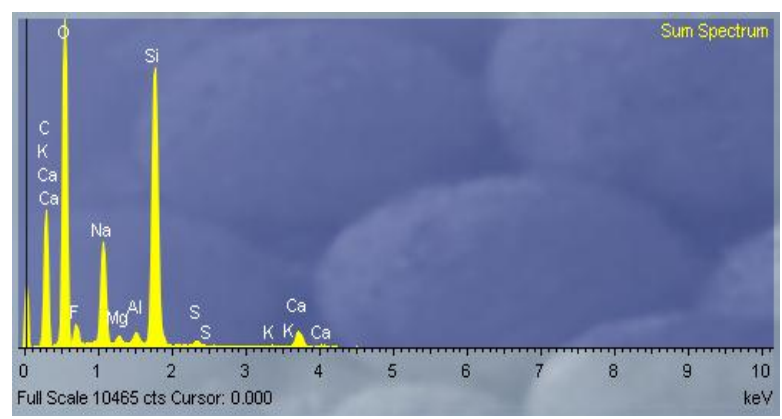

(j)

Figure 4. Glass 1st LP with different elements (a) Reference image (b) mix showing F element on the membrane surface (c) element $\mathrm{O}$ (d) element F (e) element Al (f) element Si (g) element K and (h) energy dispersion X-ray spectroscopy.

In Figure 4, the SEM and EDS results of the membrane surface layer formed on glass after $1^{\text {st }}$ LP hydrophobic nanoparticle coating are presented. All SEM photos show different spread of surface density of $\mathrm{F}, \mathrm{O}, \mathrm{Al}, \mathrm{Si}$, and $\mathrm{K}$ on the glass membrane surface. Additionally, clusters were observed on the reference image and mix $\mathrm{F}$ element. The inter-separation distances are bigger and morphology, spatial distribution, orientation, sizes and shape of F keep changing. This may indicate high surface roughness which doesn't improvement membrane wettability when related to the lotus effect on surface wettability. The lotus effect on surface wettability stated that the coated membrane surface must be smooth as smooth surface enhanced wettability. Though the inter-separation are smaller in second pressure high coating the increase in clusters in $2^{\text {nd }}$ round of coating when compared with $1^{\text {st }}$ round of coating shows $1^{\text {st }}$ HP coating will perform better than $2^{\text {nd }}$ HP coating during oil/water separation. The surface coated with hydrophobic nanoparticle revealed high $\mathrm{O}, \mathrm{Si}, \mathrm{Na}$ and $\mathrm{Ca}$ which can be correlated with the EDS and statistical analysis results as for $1^{\text {st }}$ LP coating. From the EDS it can be observed that the intensity or peak for $\mathrm{O}$ was the higher followed by $\mathrm{Si}, \mathrm{Na}$, and $\mathrm{Ca}$, while $\mathrm{S}$ was observed to have the lowest peak or intensity. A proper correlation is observed from the EDS results, statistical analysis and the SEM images. It was important to study the membrane surface after $2^{\text {nd }}$ round of coating as shown in table 4.

SOB - Series 2 Project: SOB - Series 2

Owner: INCA Operator

Site: Site of Interest 1

Sample: GLASS 2 LP Type: Default

ID: GLASS 2 LP

Table 4. Descriptive statistics of the amount of elements in the surface layer formed in glass $2^{\text {rd }}$ round LP after PEO ESD setting

\begin{tabular}{|l|l|l|l|l|l|}
\hline SOB 2Project 1 & Project & Owner & Site: & Sample & ID \\
\hline & SOB 2Project 1 & INCA Operator & Site of Interest 1 & GLASS 2 LP & GLASS 2 LP \\
\hline
\end{tabular}


International Journal of Engineering Research and Technology. ISSN 0974-3154, Volume 13, Number 5 (2020), pp. $842-866$ (C) International Research Publication House. https://dx.doi.org/10.37624/IJERT/13.5.2020.842-866

Descriptive statistics

\begin{tabular}{|l|c|c|c|c|c|c|c|c|c|c|c|}
\hline Spectrum & In stats. & $\mathrm{O}$ & $\mathrm{F}$ & $\mathrm{Na}$ & $\mathrm{Mg}$ & $\mathrm{Al}$ & $\mathrm{Si}$ & $\mathrm{S}$ & $\mathrm{K}$ & $\mathrm{Ca}$ & $\mathrm{Total}$ \\
\hline GLASS 2-S1 & Yes & 52.16 & 4.42 & 8.45 & 0.59 & 1.00 & 27.35 & 0.34 & 0.35 & 5.33 & $\begin{array}{c}100.0 \\
0\end{array}$ \\
\hline GLASS 2-S2 & Yes & 53.32 & 3.30 & 8.64 & 0.62 & 0.95 & 27.50 & 0.27 & 0.25 & 5.16 & $\begin{array}{c}100.0 \\
0\end{array}$ \\
\hline GLASS 2-S3 & Yes & 44.21 & 8.34 & 8.43 & 0.60 & 0.78 & 30.39 & 0.85 & 0.28 & 6.14 & 100.0 \\
0
\end{tabular}
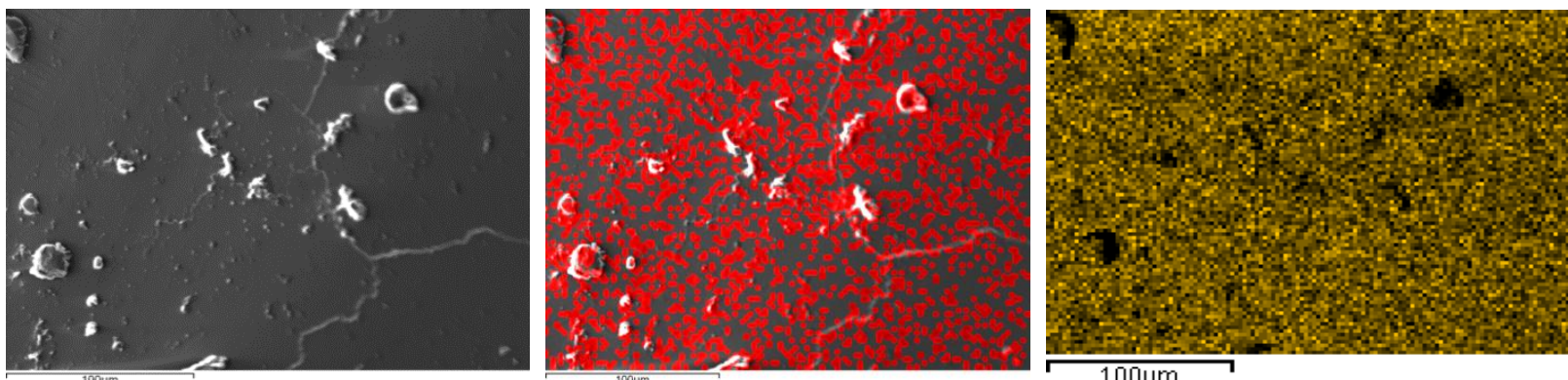

(b)

(c)

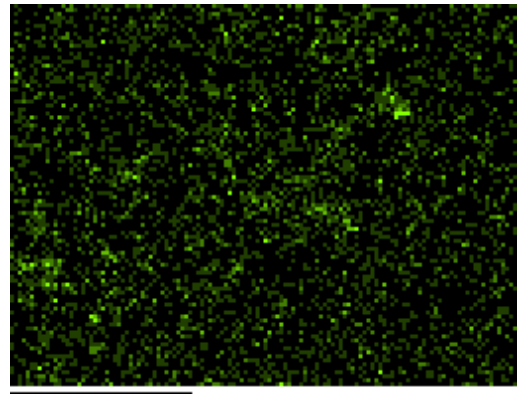

$100 \mu \mathrm{m}$

(d)

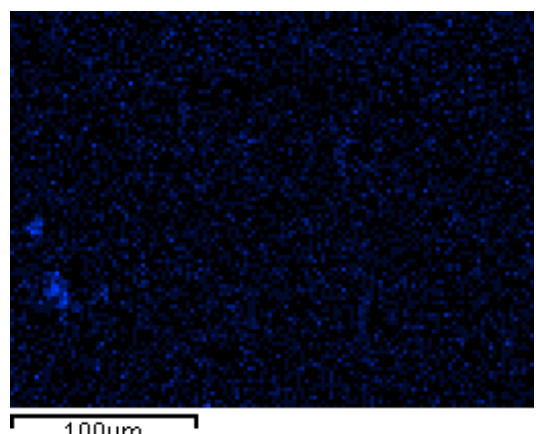

(g)

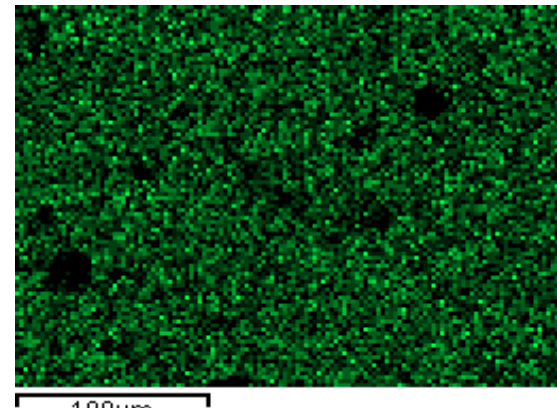

$100 \mu \mathrm{m}$

(e)

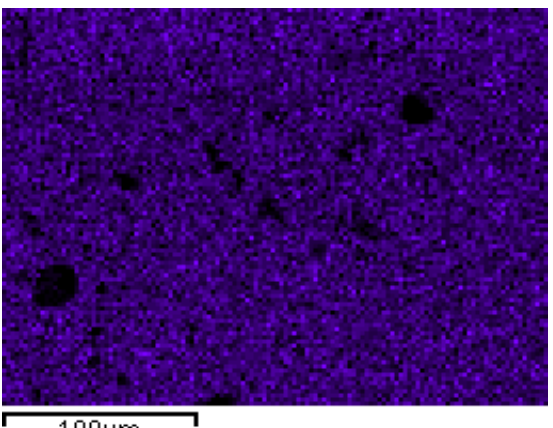

$100 \mu \mathrm{m}$

(h)

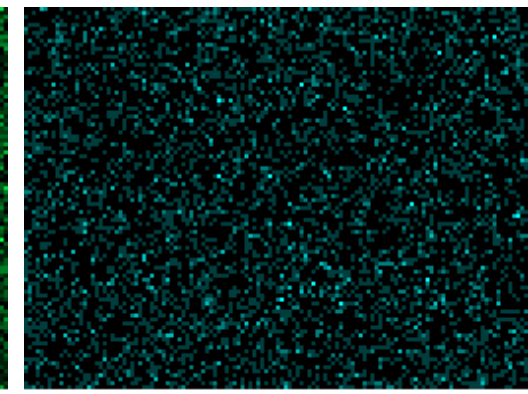

100um

(f)

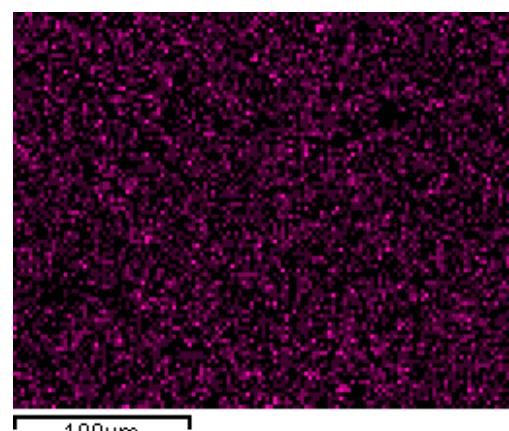

(i) 


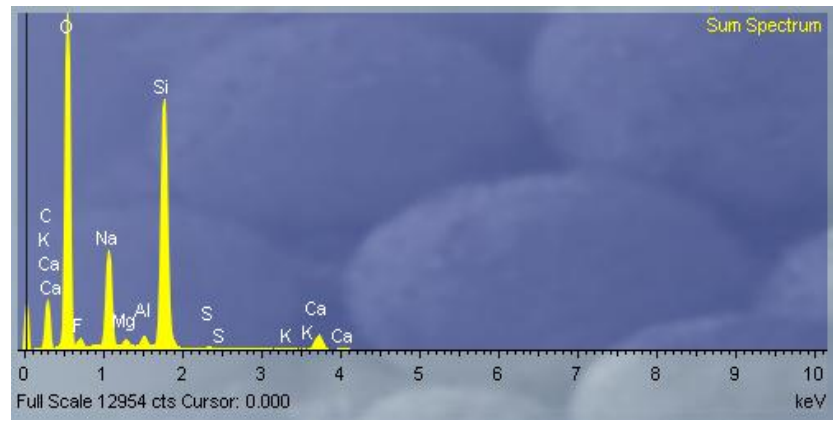

(j)

Figure 5. Glass $2^{\text {rd }}$ LP round of coating with different elements (a) Reference image (b) mix showing F element on the membrane surface (c) element $\mathrm{O}$ (d) element F (e) element Al (f) element Si (g) element K and (h) element S (i) element Mg and (j) energy dispersion X-ray spectroscopy

In Figure 5, the SEM and EDS results of membrane surface layer formed on glass after $2^{\text {rd }}$ LP hydrophobic nanoparticle coating are presented. All SEM photos show different spread of surface density of $\mathrm{F}, \mathrm{O}, \mathrm{Al}, \mathrm{Si}, \mathrm{Ca}, \mathrm{Mg}, \mathrm{Al}$ and $\mathrm{K}$ on the glass membrane surface. Additionally, more clusters are observed on the reference image and mix F element when compared with $1^{\text {st }} \mathrm{HP}$ coating. The inter-separation distances are smaller when compared to $1^{\text {st }}$ LP coating with more visible distribution of clusters, nanoparticle morphology, nanoparticle spatial distribution, change in orientation of nanoparticle, change in sizes of nanoparticle and change in shape of $F$ which affect wettability. The surface coated with hydrophobic nanoparticle revealed high $\mathrm{O}, \mathrm{Si}, \mathrm{Na}$ and $\mathrm{Ca}$ than $\mathrm{F}$ which can be correlated with the EDS and statistical analysis results as for $2^{\text {rd }} \mathrm{LP}$ coating. There secondary element over power $F$ which is the main element which improve wettability. The SEM images also revealed the surface spread of the different elements shown on the EDS and a close correlation is shown with the statistical analysis shown in table 4. From the EDS it can be observed that the intensity has a very high peak on $\mathrm{O}, \mathrm{Si}, \mathrm{Na}$, and $\mathrm{Ca}$.
The results in table 4 revealed membrane new chemical composition of glass after $2^{\text {rd }}$ round of coating by LP. Table 4 is compared with the control sample for hydrophobic nano for glass and $1^{\text {st }}$ round glass coating shown in table 3. When comparing with the original control sample of nano4glass, it was observed that $\mathrm{O}, \mathrm{Na}, \mathrm{Si}$, and $\mathrm{Ca}$ significantly increase. It was also noticed that $\mathrm{Ca}$ stayed constant and a new element of Potassium (K) was observed. The same trend was noticed for their standard deviation, Max and Min. It was necessary to observe the trend of results in LP $3^{\text {rd }}$ round of coating as shown in table 5 .

SOB - Series 2

Project: SOB - Series 2

Owner: INCA Operator

Site: Site of Interest 1 Sample: GLASS 3

Type: Default

ID: GLASS 3 LP

Table 5: Descriptive statistics of the amount of elements in the surface layer formed in glass $3^{\text {rd }}$ round LP after PEO ESD setting

\begin{tabular}{|c|c|c|c|c|c|}
\hline SOB 2Project 1 & Project & Owner & Site: & Sample & ID \\
\hline & SOB 2Project 1 & INCA Operator & Site of Interest 1 & GLASS 3 LP & GLASS 3 LP \\
\hline
\end{tabular}

Descriptive statistics

\begin{tabular}{|l|c|c|c|c|c|c|c|c|c|c|}
\hline Spectrum & In stats. & $\mathrm{O}$ & $\mathrm{F}$ & $\mathrm{Na}$ & $\mathrm{Mg}$ & $\mathrm{Al}$ & $\mathrm{Si}$ & $\mathrm{S}$ & $\mathrm{Ca}$ & $\mathrm{T}$ tal \\
\hline GLASS 3 - S1 & Yes & 45.46 & 6.38 & 8.29 & 0.60 & 0.95 & 30.69 & 0.88 & 6.76 & 100.0 \\
GLASS 3 - S1 & Yes & 45.46 & 6.38 & 8.29 & 0.60 & 0.95 & 30.69 & 0.88 & 6.76 & 0 \\
\hline GLASS 3 - S2 & Yes & 50.10 & 1.95 & 8.77 & 0.58 & 0.72 & 31.20 & 0.26 & 6.42 & 100.0 \\
GLASS 3 - S2 & Yes & 50.10 & 1.95 & 8.77 & 0.58 & 0.72 & 31.20 & 0.26 & 6.42 & 0 \\
\hline GLASS 3 - S3 & Yes & 48.44 & 6.71 & 8.44 & 0.67 & 0.97 & 28.28 & 0.83 & 5.84 & 100.0 \\
GLASS 3 - S3 & Yes & 48.44 & 6.71 & 8.44 & 0.67 & 0.79 & 28.28 & 0.83 & 5.84 & 0 \\
\hline Mean & & 48.00 & 5.02 & 8.50 & 0.62 & 0.82 & 30.05 & 0.66 & 6.34 & 100.00 \\
\hline Std. deviation & & 2.35 & 2.66 & 0.24 & 0.05 & 0.12 & 1.56 & 0.35 & 0.46 & \\
\hline Max. & & 50.10 & 6.71 & 8.77 & 0.67 & 0.95 & 31.20 & 0.88 & 6.76 & \\
\hline Min. & & 45.46 & 1.95 & 8.29 & 0.58 & 0.72 & 28.28 & 0.26 & 5.84 & \\
\hline
\end{tabular}



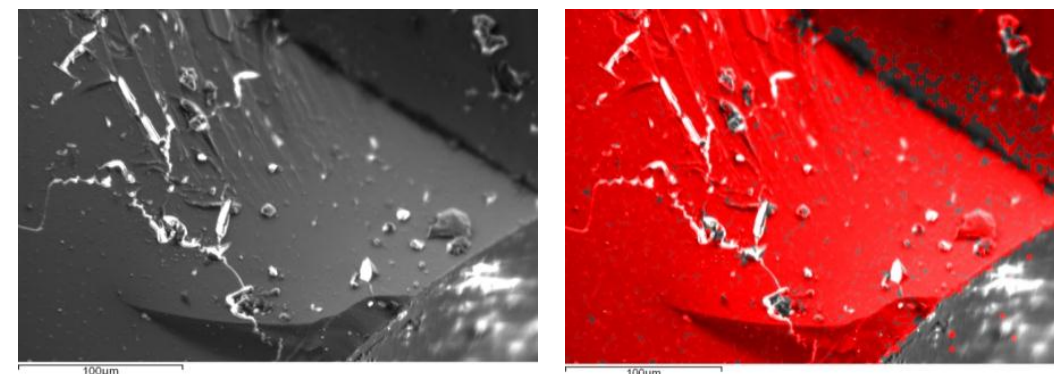

(b)

(c)

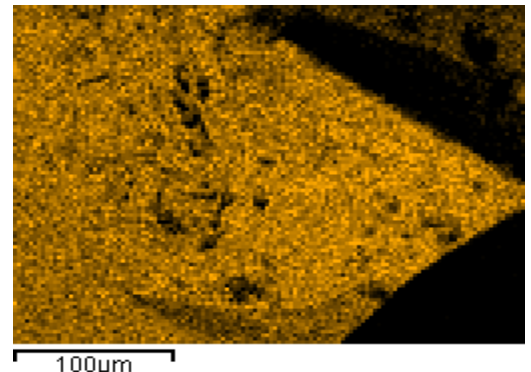

$100 \mu \mathrm{m}$

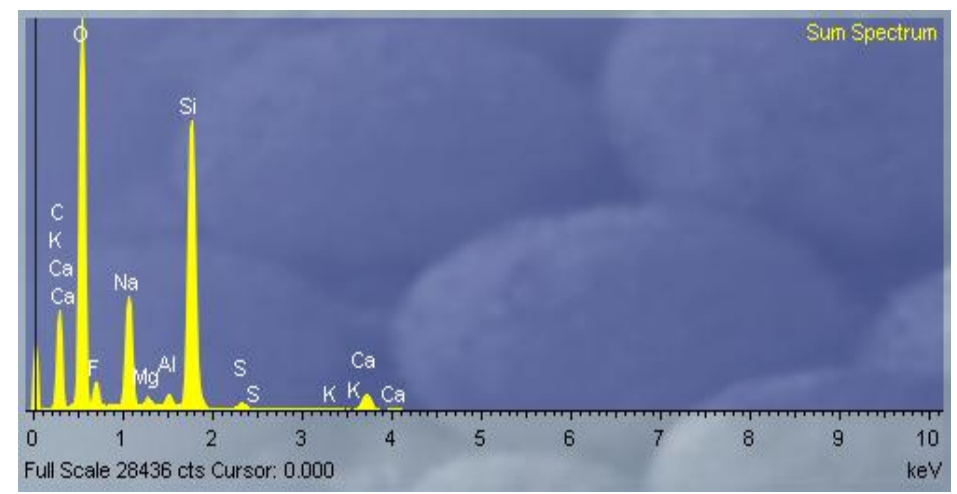

(d)

Figure 6. Glass $3^{\text {rd }}$ LP round of coating with different elements (a) Reference image (b) mix showing F element on the membrane surface (c) element $\mathrm{O}$ and (d) energy dispersion X-ray spectroscopy

In Figure 6, the SEM and EDS results of the membrane surface layer formed on glass after $3^{\text {rd }}$ LP hydrophobic nanoparticle coating are presented. All SEM photos show different spread of surface density of $\mathrm{F}$ and $\mathrm{O}$ on the glass membrane surface. Additionally, more clusters are observed on the reference image and mix $\mathrm{F}$ element when compared with $1^{\text {st }}$ LP and $2^{\text {rd }}$ LP coating. On the coated hydrophobic nanoparticle mixed surface, the inter-separation distances are very small when compared with $1^{\text {st }}$ LP coating and $2^{\text {rd }}$ LP coating. The surface coated with hydrophobic nanoparticle have high $\mathrm{O}, \mathrm{Si}, \mathrm{Na}$ and $\mathrm{Ca}$ which can be correlated with the EDS and statistical analysis results as for $3^{\text {rd }}$ LP coating.

Table 5 is compared with the control sample for nano4glass, $1^{\text {st }}$ round of glass coating and $2^{\text {nd }}$ glass coating. When comparing with the original control sample of nano4glass, it was observed that $\mathrm{O}, \mathrm{Na}$, and $\mathrm{Si}$, significantly decreased while $\mathrm{Ca}, \mathrm{Mg}$ and $\mathrm{Al}$ increases. Their mean, standard deviation, max and min after $3^{\text {rd }}$ coating for $\mathrm{O}, \mathrm{Na}, \mathrm{Mg}, \mathrm{Al}$, decreases while $\mathrm{Si}$, and $\mathrm{Ca}$ increases. When comparing with $1^{\text {st }}, 2$ rd and $3^{\text {rd }}$ round of LP coating, it was found that there was decrease in $\mathrm{O}, \mathrm{Na}$, and $\mathrm{Al}$, while $\mathrm{F}, \mathrm{S}$ and $\mathrm{Ca}$ increased. Since the produced membrane offer poor surface wettability, it was important to study HP coating and their impact on wettability.

SOB 2Project 1

Project: SOB 2Project 1

Owner: INCA Operator

Site: Site of Interest 1

Sample: GLASS HP 1

Type: Default

ID: GLASS HP 1

Table 6: Descriptive statistics of the amount of elements in the surface layer formed in glass $1^{\text {st }}$ round HP after PEO ESD setting

\begin{tabular}{|c|c|c|c|c|c|}
\hline SOB 2Project 1 & Project & Owner & Site: & Sample & ID \\
\hline & SOB 2Project 1 & INCA Operator & Site of Interest 1 & GLASS HP 1 & GLASS HP 1 \\
\hline
\end{tabular}


International Journal of Engineering Research and Technology. ISSN 0974-3154, Volume 13, Number 5 (2020), pp. $842-866$

(C) International Research Publication House. https://dx.doi.org/10.37624/IJERT/13.5.2020.842-866

\section{Descriptive statistics}

\begin{tabular}{|c|c|c|c|c|c|c|c|c|c|c|}
\hline Spectrum & In stats. & $\mathrm{O}$ & $\mathrm{F}$ & $\mathrm{Na}$ & $\mathrm{Mg}$ & $\mathrm{Al}$ & $\mathrm{Si}$ & S & $\mathrm{Ca}$ & Total \\
\hline GLASS HP 1 - S1 & Yes & \multirow{2}{*}{44.69} & \multirow{2}{*}{6.78} & \multirow{2}{*}{8.16} & 0.55 & 0.67 & 31.80 & 0.38 & 6.97 & 100.00 \\
\hline GLASS 3 - S1 & Yes & & & & 0.60 & 0.95 & 30.69 & 0.88 & 6.76 & 0 \\
\hline GLASS HP 1 - S2 & Yes & \multirow{2}{*}{53.63} & \multirow{2}{*}{1.62} & 8.04 & 0.64 & 1.00 & 28.92 & 0.74 & 5.41 & 100.00 \\
\hline GLASS 3 - S2 & Yes & & & 8.77 & 0.58 & 0.72 & 31.20 & 0.26 & 6.42 & 0 \\
\hline GLASS HP 1 - S3 & Yes & \multirow{2}{*}{52.23} & \multirow{2}{*}{4.59} & 8.72 & 0.70 & 0.70 & 27.24 & 0.43 & 5.39 & 100.0 \\
\hline GLASS 3 - S3 & Yes & & & 8.44 & 0.67 & 0.79 & 28.28 & 0.83 & 5.84 & 0 \\
\hline Mean & & 50.18 & 4.33 & 8.31 & 0.63 & 0.79 & 29.32 & 0.52 & 5.92 & 100.00 \\
\hline Std. deviation & & 4.81 & 2.59 & 0.36 & 0.07 & 0.18 & 2.31 & 0.19 & 0.91 & \\
\hline Max. & & 53.63 & 6.78 & 8.72 & 0.70 & 1.00 & 31.80 & 0.74 & 6.97 & \\
\hline Min. & & 44.69 & 1.62 & 8.04 & 0.55 & 0.67 & 27.24 & 0.38 & 5.39 & \\
\hline
\end{tabular}

All results in weight $\%$
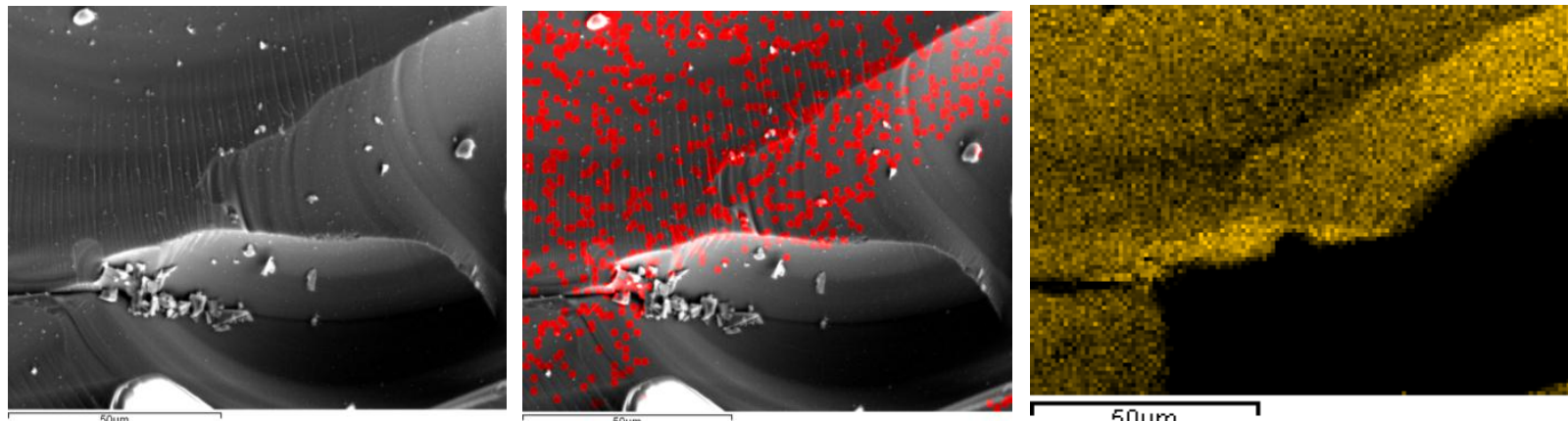

(b)

(c)

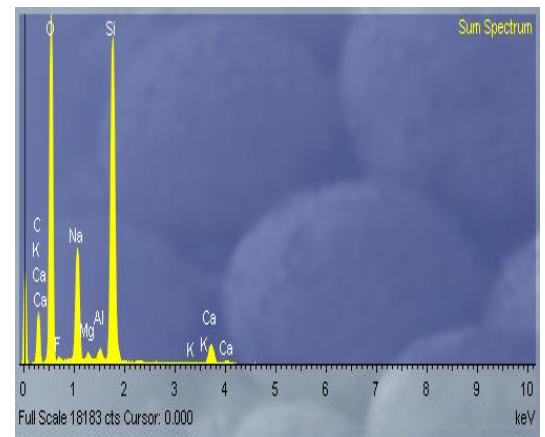

(d)

Figure 7. Glass $1^{\text {st }}$ HP round of coating with different elements (a) Reference image (b) mix showing F element on the membrane surface (c) element $\mathrm{O}$ and (d) energy dispersion $\mathrm{X}$-ray spectroscopy.

In Figure 7, the SEM and EDS results of the membrane surface layer formed on glass after $1^{\text {st }} \mathrm{HP}$ hydrophobic nanoparticle coating are presented. All SEM photos show different spread of surface density of $\mathrm{F}$ and $\mathrm{O}$ on the glass membrane surface. Additionally, few clusters are observed on the reference image and mix $\mathrm{F}$ element when compared with $1^{\text {st }}$ LP, $2^{\text {rd }}$ LP and $3^{\text {rd }}$ LP coating. The inter-separation distances are big creating rough membrane surface. The 
International Journal of Engineering Research and Technology. ISSN 0974-3154, Volume 13, Number 5 (2020), pp. $842-866$

(C) International Research Publication House. https://dx.doi.org/10.37624/IJERT/13.5.2020.842-866

orientation of nanoparticles, morphology, spread, spatial distribution, and size of nanoparticles are random. The surfaces coated with hydrophobic nanoparticle have high $\mathrm{O}$, $\mathrm{Si}, \mathrm{Na}$ and $\mathrm{Ca}$ which over powered $\mathrm{F}$ and this can be correlated with the EDS and statistical analysis results. Due to few membrane clusters being observe and due to the fact that the membrane inter-separation distance were big the wettability membrane for somehow efficient during oil/water separation. There was not a need to study $2^{\text {nd }}$ round HP coating to see if the produced membrane surface will be more efficient with stable wettability.
SOB - Series 2

Project: SOB - Series 2

Owner: INCA Operator

Site: Site of Interest 1

Sample: GLASS HP 2

Type: Default

ID: GLASS HP 2

Table 7: Descriptive statistics of the amount of elements in the surface layer formed in glass $2^{\text {rd }}$ round HP after PEO ESD setting

\begin{tabular}{|c|c|c|c|c|c|}
\hline SOB 2Project 1 & Project & Owner & Site: & Sample \\
\hline & SOB 2Project 1 & INCA Operator & Site of Interest 1 & GLASS HP 2 & GLASS HP 2 \\
\hline
\end{tabular}

Descriptive statistics

\begin{tabular}{|l|c|c|c|c|c|c|c|c|c|c|c|}
\hline Spectrum & In stats. & $\mathrm{O}$ & $\mathrm{F}$ & $\mathrm{Na}$ & $\mathrm{Mg}$ & $\mathrm{Al}$ & $\mathrm{Si}$ & $\mathrm{S}$ & $\mathrm{K}$ & $\mathrm{Ca}$ & $\mathrm{Total}$ \\
\hline $\begin{array}{l}\text { GLASS HP 2 - S1 } \\
\text { GLASS 3 - S1 }\end{array}$ & $\begin{array}{c}\text { Yes } \\
\text { Yes }\end{array}$ & 54.00 & 1.09 & 9.01 & $\begin{array}{c}0.57 \\
0.60\end{array}$ & $\begin{array}{c}0.75 \\
0.95\end{array}$ & 28.52 & 0.25 & 0.21 & 5.59 & $\begin{array}{c}100.00 \\
0\end{array}$ \\
\hline $\begin{array}{l}\text { GLASS HP 2 - S2 } \\
\text { GLASS 3 - S2 }\end{array}$ & $\begin{array}{c}\text { Yes } \\
\text { Yes }\end{array}$ & 49.69 & 2.96 & 8.68 & $\begin{array}{c}0.63 \\
0.58\end{array}$ & 0.83 & 30.34 & 0.62 & 0.18 & $\begin{array}{c}6.06 \\
6.42\end{array}$ & $\begin{array}{c}100.00 \\
0\end{array}$ \\
\hline $\begin{array}{l}\text { GLASS HP 2 - S3 } \\
\text { GLASS 3 - S3 }\end{array}$ & $\begin{array}{l}\text { Yes } \\
\text { Yes }\end{array}$ & 46.89 & 4.52 & 8.07 & $\begin{array}{c}0.66 \\
0.67\end{array}$ & 0.74 & 30.53 & 1.50 & 0.54 & $\begin{array}{c}6.54 \\
5.84\end{array}$ & $\begin{array}{c}100.00 \\
0\end{array}$ \\
\hline Mean & & 50.19 & 2.86 & 8.59 & 0.62 & 0.77 & 29.80 & 0.79 & 0.31 & 6.07 & 100.00 \\
\hline Std. deviation & & 3.58 & 1.72 & 0.48 & 0.05 & 0.05 & 1.11 & 0.64 & 0.20 & 0.47 & \\
\hline Max. & & 54.00 & 4.52 & 9.01 & 0.66 & 0.83 & 30.53 & 1.50 & 0.54 & 6.54 & \\
\hline Min. & & 46.89 & 1.09 & 8.07 & 0.57 & 0.74 & 28.52 & 0.25 & 0.18 & 5.59 & \\
\hline
\end{tabular}

All results in weight $\%$

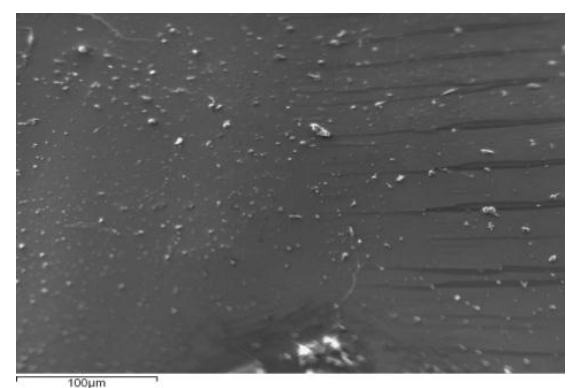

(a)

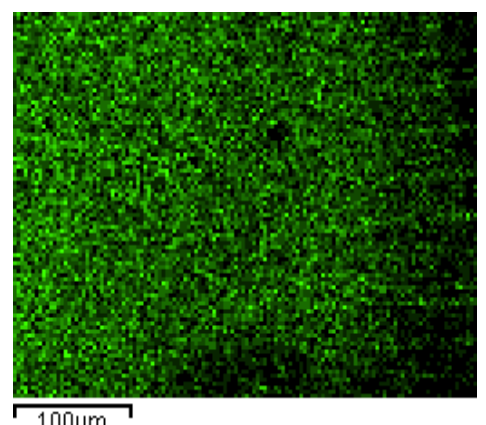

(d)

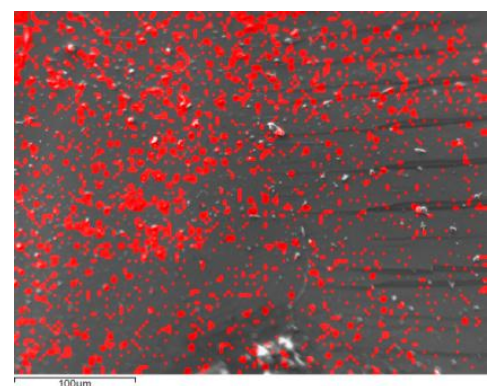

(b)

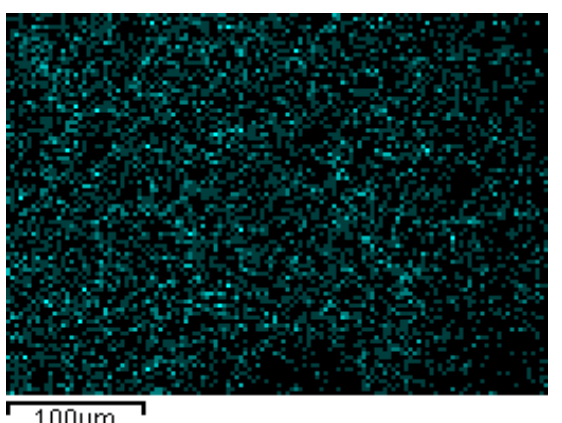

(e)

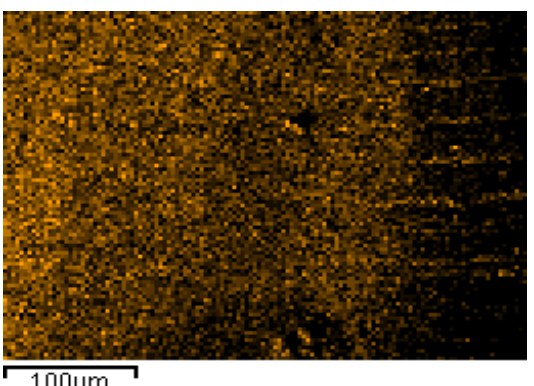

(c)

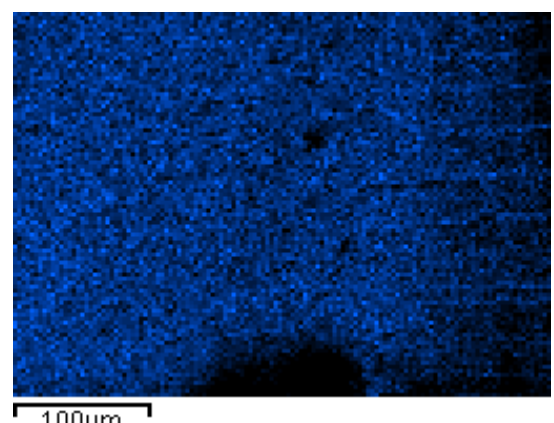

(f) 


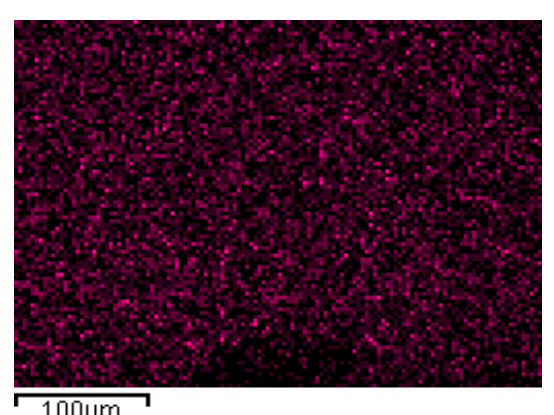

(g)

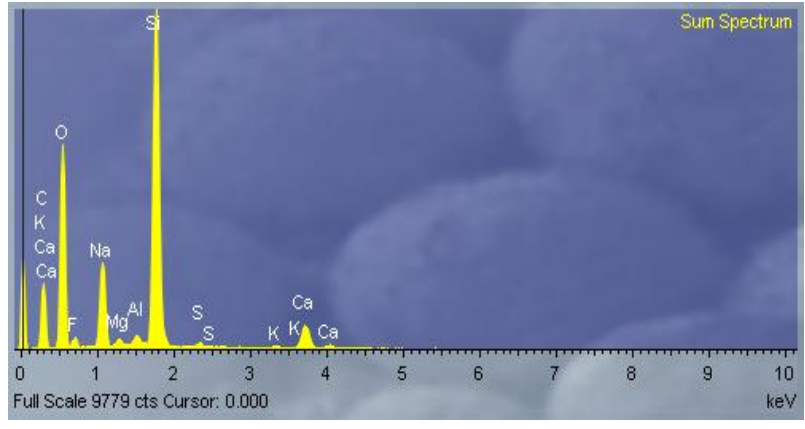

(h)

Figure 8. Glass $2^{\text {rd }}$ HP round of coating with different elements (a) Reference image (b) mix showing F element on the membrane surface (c) element $\mathrm{O}$ (d) element $\mathrm{Na}$ (e) element Al (f) element Si (g) element K and (h) energy dispersion X-ray spectroscopy

In Figure 8, the SEM and EDS results of the membrane surface layer formed on glass after $2^{\text {nd }}$ HP hydrophobic nanoparticle coating are presented. All SEM photos show different spread of surface density of F, O, Na, Al, Si and K on the glass membrane surface. Additionally, more clusters are observed on the reference image and mix $\mathrm{F}$ element when compared with $1^{\text {st }}$ HP coating. Though the F interseparation distances are smaller when compared with $1^{\text {st }} \mathrm{HP}$ coating more clusters created rougher membrane surface leading to inefficient wettability process. The EDS results and statistical analysis revealed data that shows close correlation between the SEM images when comparing the different intensity of the elements. It was necessary to analysed glass $3^{\text {rd }} \mathrm{HP}$ coating.

SOB - Series 2

Project: SOB - Series 2

Owner: INCA Operator

Site: Site of Interest 1

Sample: GLASS HP 3

Type: Default

ID: GLASS HP 3

Table 8. Descriptive statistics of the amount of elements in the surface layer formed in glass $3^{\text {rd }}$ round HP after PEO ESD setting

\begin{tabular}{|c|c|c|c|c|c|}
\hline SOB 2Project 1 & Project & Owner & Site: & Sample & ID \\
\hline & SOB 2Project 1 & INCA Operator & Site of Interest 1 & GLASS HP 3 & GLASS HP 3 \\
\hline
\end{tabular}

Descriptive statistics

\begin{tabular}{|c|c|c|c|c|c|c|c|c|c|c|}
\hline Spectrum & In stats. & $\mathrm{O}$ & $\mathrm{F}$ & $\mathrm{Na}$ & $\mathrm{Mg}$ & $\mathrm{Al}$ & $\mathrm{Si}$ & S & $\mathrm{Ca}$ & Total \\
\hline $\begin{array}{l}\text { GLASS HP } 3 \text { - S1 } \\
\text { GLASS } 3 \text { - S1 }\end{array}$ & $\begin{array}{l}\text { Yes } \\
\text { Yes }\end{array}$ & 54.79 & 2.75 & 9.36 & $\begin{array}{l}0.72 \\
0.60\end{array}$ & $\begin{array}{l}0.82 \\
0.95\end{array}$ & $\begin{array}{l}23.81 \\
30.69\end{array}$ & $\begin{array}{l}2.75 \\
0.88\end{array}$ & $\begin{array}{l}5.01 \\
6.76\end{array}$ & $\begin{array}{c}100.00 \\
0\end{array}$ \\
\hline $\begin{array}{l}\text { GLASS HP } 3 \text { - S2 } \\
\text { GLASS } 3 \text { - S2 }\end{array}$ & $\begin{array}{l}\text { Yes } \\
\text { Yes }\end{array}$ & 53.33 & 1.54 & $\begin{array}{l}8.76 \\
8.77\end{array}$ & $\begin{array}{l}0.54 \\
0.58\end{array}$ & $\begin{array}{l}0.77 \\
0.72\end{array}$ & $\begin{array}{l}29.45 \\
31.20\end{array}$ & 0.26 & $\begin{array}{l}5.61 \\
6.42\end{array}$ & $\begin{array}{c}100.00 \\
0\end{array}$ \\
\hline $\begin{array}{l}\text { GLASS HP } 3 \text { - S3 } \\
\text { GLASS } 3 \text { - S3 }\end{array}$ & $\begin{array}{l}\text { Yes } \\
\text { Yes }\end{array}$ & 51.82 & 2.11 & $\begin{array}{l}8.76 \\
8.44\end{array}$ & $\begin{array}{l}0.57 \\
0.67\end{array}$ & $\begin{array}{l}1.35 \\
0.79\end{array}$ & $\begin{array}{l}29.04 \\
28.28\end{array}$ & $\begin{array}{l}0.46 \\
0.83\end{array}$ & $\begin{array}{l}5.85 \\
5.84\end{array}$ & $\begin{array}{c}100.00 \\
0\end{array}$ \\
\hline Max. & & 54.79 & 2.75 & 9.36 & 0.72 & 1.35 & 29.45 & 2.75 & 5.85 & \\
\hline Min. & & 51.86 & 1.54 & 8.76 & 0.54 & 0.77 & 23.81 & 0.46 & 5.01 & \\
\hline
\end{tabular}

All results in weight $\%$ 


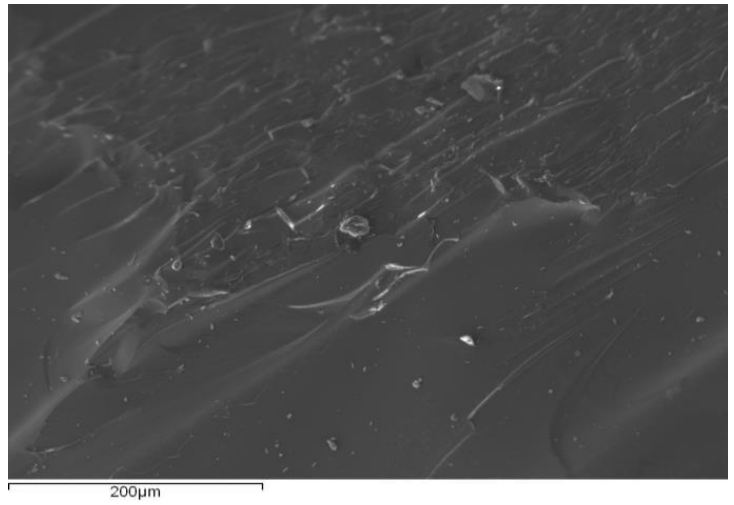

(a)

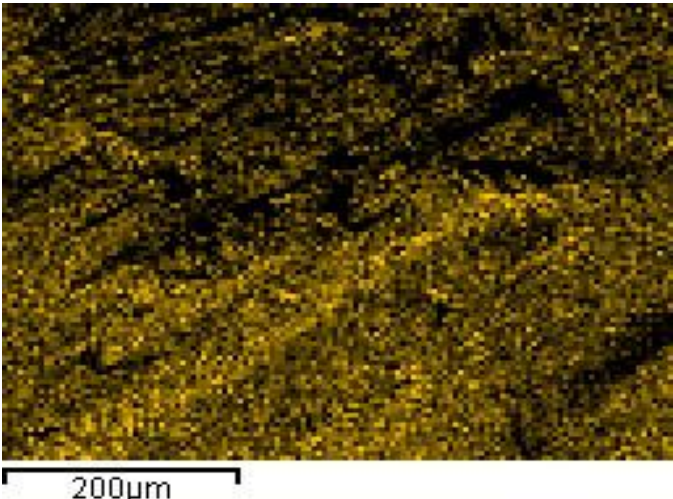

(b)

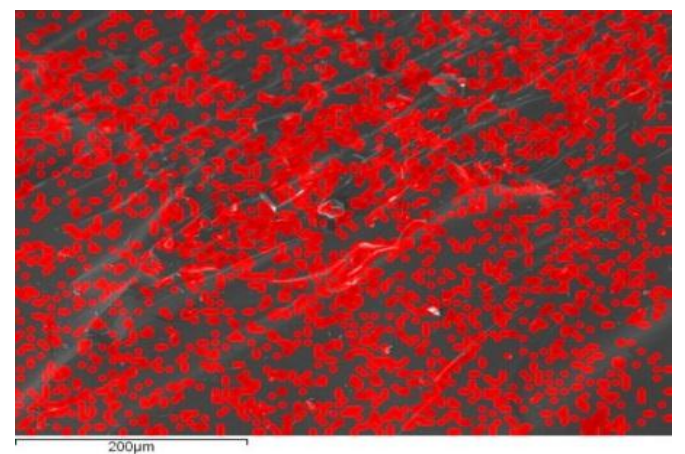

(c)

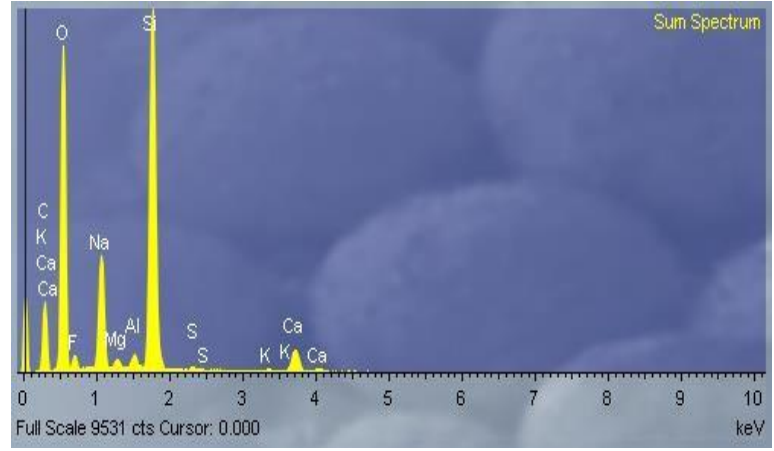

(d)

Figure 8. Glass $3^{\text {rd }} \mathrm{HP}$ round of coating with different elements (a) Reference image (b) element $\mathrm{O}$ (c) mix showing F element on the membrane surface $(\mathrm{d})$ energy dispersion X-ray spectroscopy

In Figure 8, the SEM and EDS results of the membrane surface layer formed on glass after $3^{\text {st }}$ HP hydrophobic nanoparticle coating are presented. All SEM photos show different spread of surface density of $\mathrm{F}$ and $\mathrm{O}, \mathrm{Na}$ on the glass membrane surface. Additionally, few clusters are observed on the reference image and mix $F$ element when compared with $1^{\text {st }} \mathrm{HP}, 2^{\text {rd }} \mathrm{HP}, 1^{\text {st }} \mathrm{LP}, 2^{\text {nd }} \mathrm{LP}$ and $3^{\text {rd }} \mathrm{LP}$ coating. The inter-separation distances are smaller when compared with $1^{\text {st }}$ and $2^{\text {nd }}$ HP coating. The smaller nanoparticles inter-separation distances have more impact on membrane wettability. Very few clusters are also observed in $3^{\text {rd }}$ HP coating and the membrane surface appear smoother with proper nanoparticles orientation, morphology and distribution due to absence of cluster. Materials are called nanoparticles due to their reduced sizes and enhanced properties. It can be concluded that when nanoparticles size, orientation, morphology and distribution evolve with few clusters and smaller inter-separation distance, the wettability surface is more enhanced during oil/water separation. This is an indication that the membrane wettability is more enhanced in in $3^{\text {rd }} \mathrm{HP}$ coating when compared with other coating round in HP and LP. It was necessary to derive mathematical models of the observed nanoparticles scattering on the membrane surface during coating process.

\subsection{Modelling membrane inter-separation distances during membrane coating}

To model nanoparticle coating inter-separation distance during membrane coating, it was observed through microscopy observation that the mean inter-particle distance of nanoparticle during coating is proportional to the size perparticle volume given as $r=\frac{1}{n^{1 / 3}} . \quad$ where $n=\frac{P_{N}}{V}$ the nanoparticle surface density on the membrane is pores. Due to the spherical nature of nanoparticles size, the radius of the spherical nanoparticle can be given as $(3 / 4 \pi n)^{1 / 3}$. It was also observed from microscopy observation that if the nanoparticle is at a given distance, the probability of the nanoparticle from the distance of the origin where coating takes place is given as $\left(\frac{4 \pi r^{2}}{3 V}\right) d r$, and the probability function away from a given circular point of coating is $1+4 \pi r^{2} / 3 \mathrm{~V}$. Therefore the expression for the probabilistic function can be define based on microscopy observation as

$$
P_{P_{N}}(r) s d r=4 / 3 \pi r^{2} d r\left(\frac{P_{N}}{V}\right)\left(1+\pi \frac{r^{3}}{V}\right)^{P_{N}-1}
$$

Where $\mathrm{r}$ is the size of nanoparticle, $P_{P N}$ is the assumed nanoparticle inside the sphere having a volume given as $\frac{4}{3} \pi \mathrm{PNr}^{3}$. Substituting the volume in equation (1) gave an expression of Wigner-Seltze radius which is a discrete process 
given as

$P_{P_{N}}(r) s d r=4 / 3 \pi r^{2} d r\left(\frac{P_{N}}{\frac{4}{3} \pi P_{N r^{3}}}\right)\left(1+\pi \frac{r^{3}}{\frac{4}{3} \pi P_{N r^{3}}}\right)^{P_{N-1}}$

Equation (2) gives the change in nanoparticle sizes on membrane inter-separation distances during coating. From equation (2) it is important to study the effect of membrane inter-separation distance with respect to very small infinite change in particle inside sphere during coating. This is possible when taking into consideration the limit of a very small change in particle distance during coating as the interseparation distances decreases during coating as observed from the microscopy. The expression for this infinite change is given as $P_{N \rightarrow \infty}=\lim _{r \rightarrow \infty}\left(1+\frac{1}{r}\right)^{r}$. Therefor the limit defined the infinite change in inter-separation distance during nanoparticle coating.

The infinite change in particle size on membrane interseparation distances is affected by adhesive energy or the bonding energy of the nanoparticle during coating. Membrane adhesive energy drives membrane nanoparticle in the membrane pore sizes. The membrane adhesive energy also affects the contact area between nanoparticle scattering, surface energy, surface tension, surface resistance and shear stress resistance during coating. These parameters affect the total force on the membrane during coating as shown in Fig. 9.

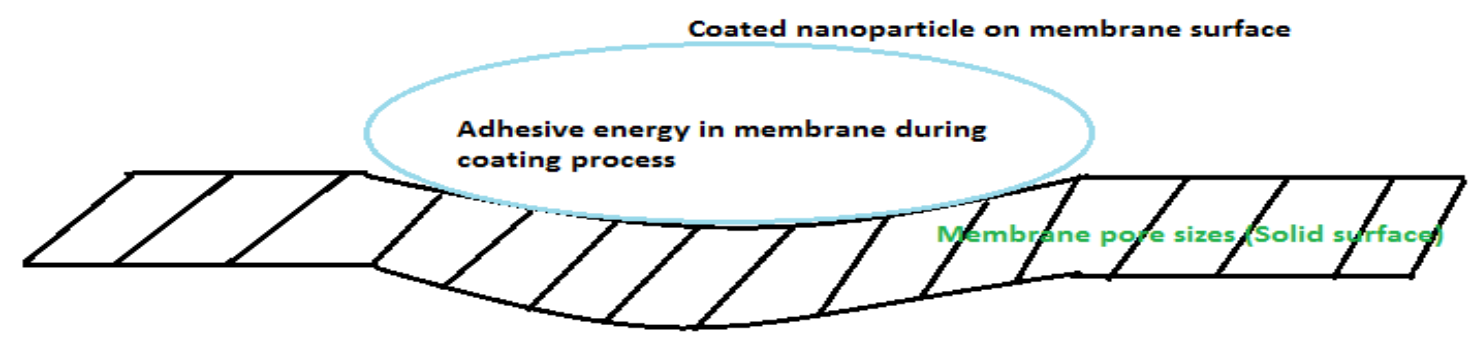

Figure 9. Nanoparticle coating on solid membrane and adhesive energy during coating process.

The energy of adhesion which is the energy released when nanoparticle liquid comes in contact with the membrane during coating can be defined by taking the different forces that affect membrane wettability as shown in figure 9. The membrane surface morphology (rough or smooth) which led to the frictional force that affect the surface energy in the membrane surface played a major role on how the spherical or closely nanoparticles flew through the membrane during coating. Another observed force during the coating process was the reaction force from the nanoparticle during coating. The forces acting on the membrane during coating are the force from nano-particle $\left(F_{\text {nano }}\right)$ which lowers the membrane surface energy. There is the force of viscosity $\left(\mathrm{F}_{\text {viscosity }}\right)$ due to the flow of nanoparticle during coating. There is the force on pressure due to high pressure or low pressure during coating ( $\left.F_{\text {pressure }}\right)$. There is the force on solid wall and pressure during coating $\left(\mathrm{F}_{\text {down }}\right)$. There is the force on wall and oil $\left(\mathrm{F}_{\text {upward }}\right)$ and there is the force of friction $\left(F_{\text {friction }}\right)$, force of alcohol during coating in the nanoparticle

\section{(Fforce of flourine), Force of demineralise water}

(Fdemineralised water).

These forces are shown in the schematic in Fig.10.

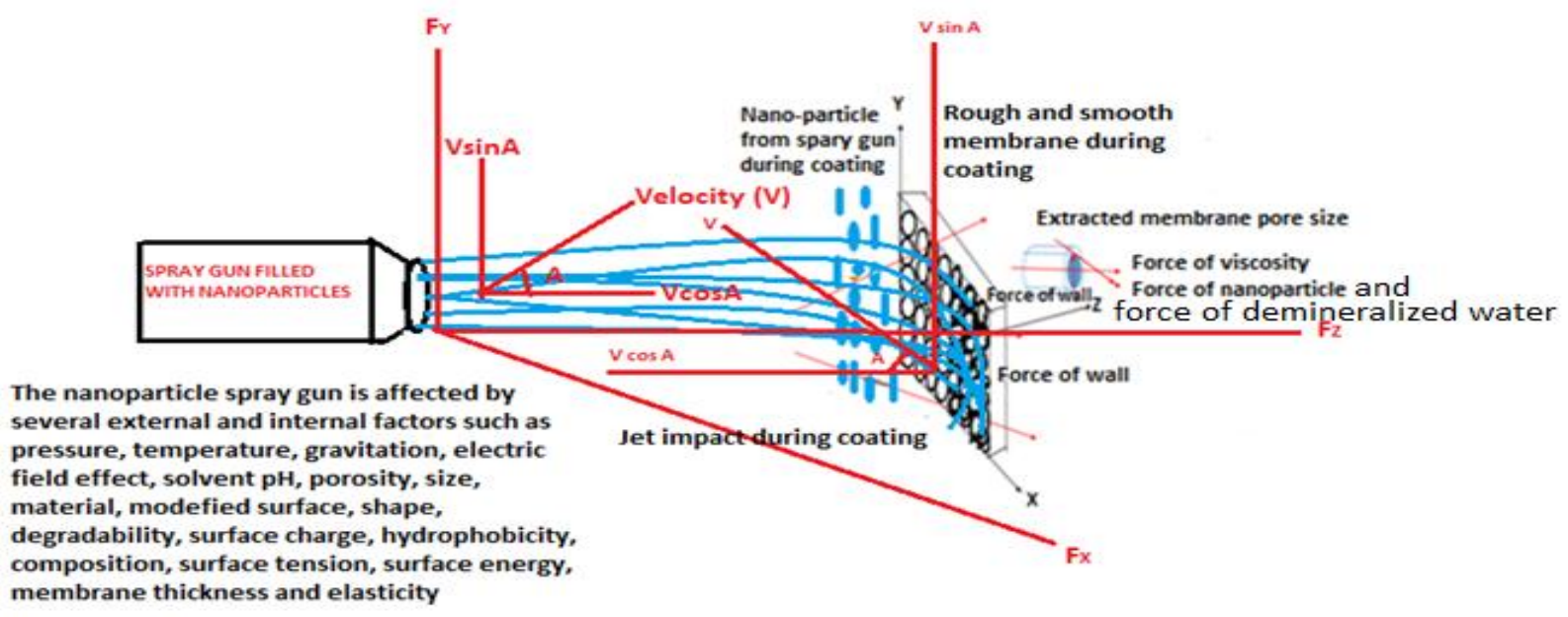

Figure 10. Schematic of jet impact propulsion during nano-coating process and membrane external and internal factors during nanoparticle coating process. 
During nanoparticle coating the jet impact and the jet propulsion depend on the following parameters (viscosity, velocity and the geometry of the membrane pore size). These parameters affect the nanoparticle thickness and membrane inter-separation distance during coating. Before membrane coating takes place, it was observed and assumed that the glass surfaces were smooth and the loss of energy due to the jet impact was zero. The velocity of nanoparticle at the outlet tip of the jet spray which was circular in diameter impacted the coated material with a velocity $(\mathrm{V})$ and the forces being exerted by the spray gun to the nanoparticle along the $\mathrm{x}$-axis, $\mathrm{y}$-axis and $\mathrm{z}$-axis are given as

$F_{z}=\frac{\operatorname{mass}}{\sec }\left[V_{1 z}-V_{2 z}\right]=\rho a V\left[V_{\cos A}+V_{\cos A}\right]=2 \rho a V^{2} \cos A$

$F_{y}=\frac{\operatorname{mass}}{\sec }\left[V_{1 y}-V_{2 y}\right]=\rho a V\left[V_{\sin A}-V_{\sin A}\right]=0$

$F_{x}=\frac{\operatorname{mass}}{\sec }\left[V_{1 x}-V_{2 x}\right]=\rho a V[0+0]=0$

where $a$ the cross section area of the jet gun spray, $\rho$ is the density of nanoparticle coating in $\mathrm{kg} / \mathrm{m}^{3}, V_{1 z}, V_{1 y}$ and $V_{1 x}$ are the initial velocities in the directions of jet spray gun and $V_{2 z}, V_{2 y}$ and $V_{2 x}$ are the final velocities in the direction of the jet spray gun. Therefore the expression of the total force in the membrane surface during coating is given as

$F_{\text {Total }}=F_{\cos \theta}+F_{\text {Viscosity }}+$

$F_{\text {upward (solid and nanoparticle coating) }}$

$F_{\text {down (solid and nanoparticle coating) }}+$

$F_{\text {pressure due to jet spray gun ( } H P \text { and } L P)}-$

$F_{\text {friction due to reaction from the wall }}+F$ force of alcohol +

$F$ demineralised water $+2 \rho a V^{2} \cos A$

The total forces given in equation (6) affect the membrane inter-separation distances during coating. This also affect the contact area between nanoparticle coating, surface energy, surface tension, surface resistance and shear stress resistance, viscosity and the geometry of the membrane. Therefore it is very important to understand the effect of membrane inter-

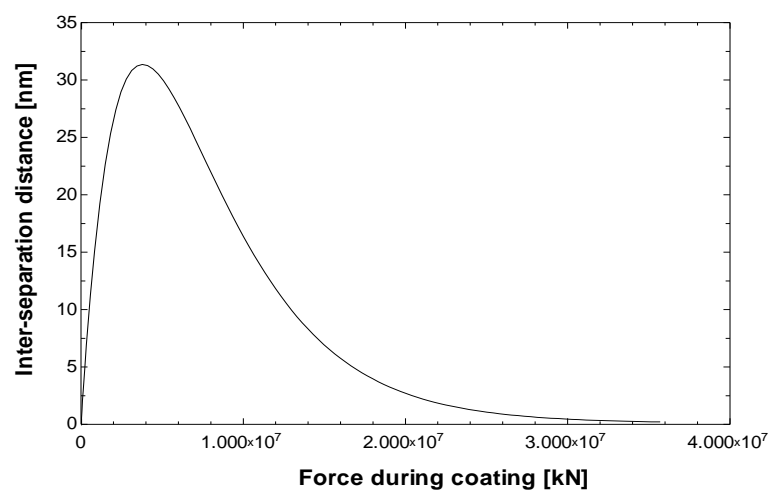

(a) separation distances during coating. From first principle, surface energy is defined as the work done per unit area given by

$$
\text { energy }=\frac{W}{A}=\frac{F_{\text {Total }} \cdot S}{A}=\delta_{\text {energy }}=\frac{F_{\text {Total }} \Delta S}{2 \pi r S_{1}}
$$

where $\mathrm{W}$ is the work done and $A=2 \quad r S$ is the surface area of the membrane channel and $\mathrm{S}$ the length of the membrane surface from which the surface energy is measured. Similarly the relationship that describes force per-unit length in a surface can be described using surface tension. The expression is given as

$$
\delta_{\text {Tension }}=\frac{F_{\text {Total }}}{2 \pi r S_{1}}
$$

where $\mathrm{S} 1$ is the external distance of the membrane external surface. The membrane surface energy and surface tension given by equation (7-8) depends on membrane forces and scattering of coated nanoparticles that lower surface energy to improve wettability. To improve membrane wettability the coated nanoparticles in the membrane surface must have the optimal inter-separation distances during nanoparticle coating. From expression (7-8), the effect of the nanoparticle coating inter-separation distance $s d r$ on surface tension and surface energy can be inferred to study their effect on wettability. It should be recalled that the nanoparticles are coated on the membrane surface with some spacing between them called the inter-separation distances as established in equation (2) and this spacing affect membrane surface tension and surface energy which affect membrane wettability. Equations (1-8) are solved simultaneously using Engineering Equation Solver software (F-Chart Software, Madison, W153744, USA)

\subsection{RESULTS AND DISCUSSION}

The proposed models derived in this paper are tested with the following data $\rho=1000 \mathrm{~kg} / \mathrm{m}^{3}, \mathrm{~S}_{1}=0.3 \mathrm{~m}, \mathrm{Vvol}=0.12 \mathrm{~m}^{3}, \mathrm{t}_{2}$ $=150 \mathrm{sec}, \mathrm{t}_{3}=120 \mathrm{sec}, \mathrm{A}_{1}=0.08 \mathrm{~m}, \mathrm{~A}_{2}=0.04 \mathrm{~m}, \mathrm{~F}=100$ KN. The obtained results are presented and discussed in Fig.4Fig.8

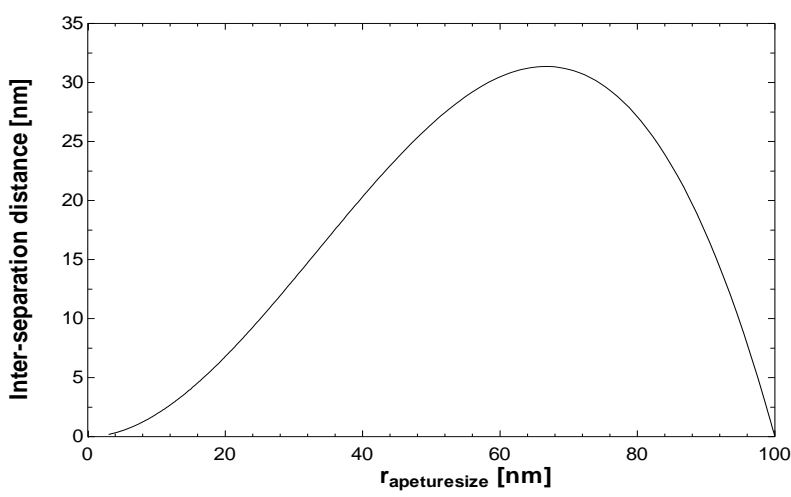

(b) 


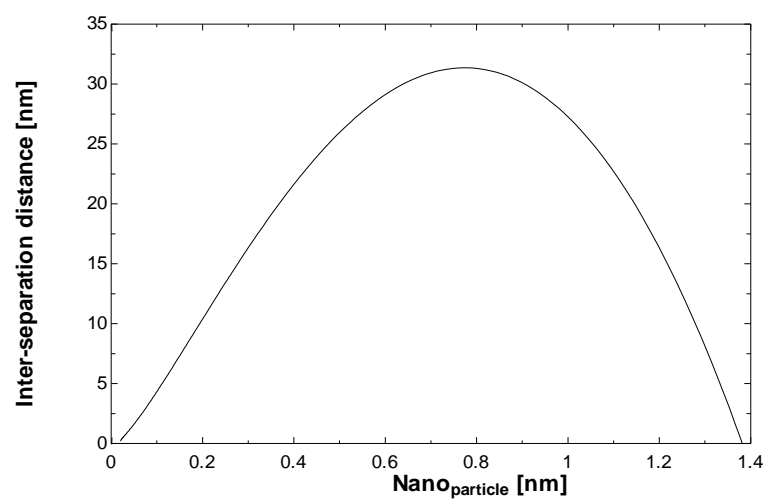

(c)

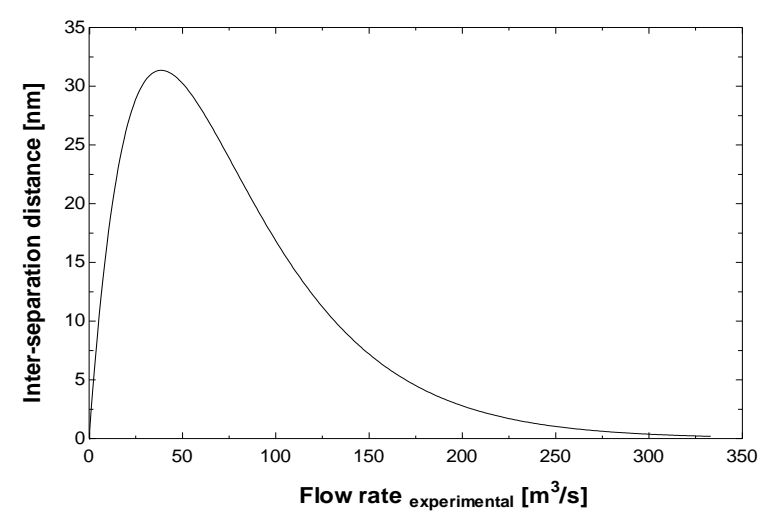

(e)

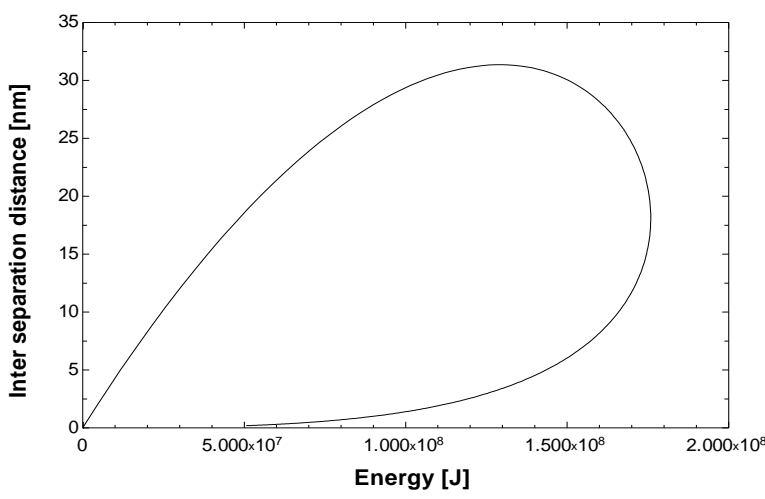

(d)

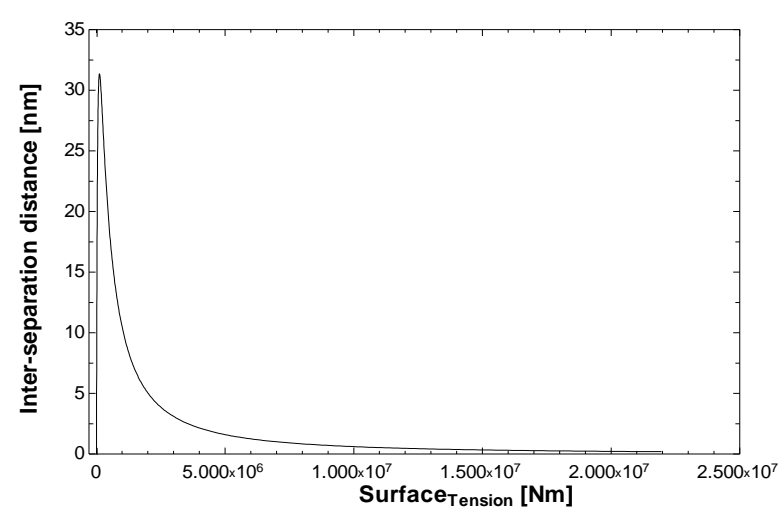

(f)

Figure 11. (a) Inter-separation distance [nm] against Force during membrane coating [kN] (b) Inter-separation distance [nm] against apeture size [nm] (c) Inter-separation distance [nm] against nanoparticle sizes [nm] (d) Inter-separation distance [nm] against energy during coating $[\mathrm{J}]$ (e) Inter-separation distance [ $\mathrm{nm}]$ against against membrane flow rate [m3/s] (f) Inter-separation distance $[\mathrm{nm}]$ against surface tension $[\mathrm{Nm}]$.

The results shown in Fig.11 (a-f) shown that inter-separation distances greatly affect membrane wettability. It is revealed that the decrease in nanoparticle sizes during nanoparticle scattering which affects wettability, leads to increase in membrane surface energy i.e increase hydrophobicity during membrane coating during the initial process of nanoparticle coating. It is also revealed that the continuous decrease of the nanoparticles on the membrane surface during coating did not lead to increase in energy in the membrane surface during wettability since the membrane surface became smother or less rough due to varying nanoparticle scattering on the membrane surface which impacted wettability. The result revealed an increase and decrease in membrane interseparation distances during nanoparticle coating as shown in Fig. 11 (a). It was also revealed from Fig. 11 (b-c) that there was a critical nanoparticles size during coating below which continuous coating of the membrane surface with nanoparticles led to decrease in inter-separation distances and surface energy which impact membrane wettability or flow rate as shown in Fig.11 (e), leading to hydrophilic surface.

The results revealed in this study showed a smooth transition from higher surface energy due to proper membrane interseparation distances which lower surface energy. There was also a maximum energy and maximum inter-separation distances during membrane coating where surface energy started decreasing leading to enhancement on wettability or flow rate, but with poor membrane separability since oil and water flew through the membrane surface leading to ineffective wettability. The reasons for the increasing-todecreasing surface energy and inter-separation distances with decreasing in nanoparticle sizes were explained to be due to nanoparticle scattering which changes the aperture roughness and smoothness. It could be proposed from this study that the optimal membrane separability during wettability where the oil mixture ratio was low was actually when the surface energy was highest during membrane wettability although the flow rate was low due to the fact that the surface was highly hydrophobic at that point due to poor nanoparticle scattering on the membrane surface with higher membrane interseparation distances.

During nanoparticles coating process, when nanoparticles were coated on the membrane surfaces, particles scattered through the membrane surfaces creating surface roughness. The rough membrane surfaces created higher surface energy and their inter-separation distances were higher with negative impact on membrane wettability or flow rate. As more coating 
takes place specifically $2^{\text {rd }}$ and $3^{\text {rd }}$ coating, the roughness of the surfaces decreased due to deceased inter-separation distances thereby creating smoother membrane surfaces and the membrane surface energy started decreasing leading to improvement on wettability or flow rate. Therefore the result in this study indicated that the effect of roughness to smoothness due to change in membrane inter-separation distances was a consequence of continuous coating from $1^{\text {st }}$ to $3^{\text {th }}$ coating.

Several researchers have described membrane roughness and smoothness by their contact angles (1-14) and their impacts on membrane wettability. Few researchers have looked at membrane inter-separation distances and their effect on wettability which is the focus of this research. Smooth membrane surfaces are due to proper membrane coating process where the scattering of nanoparticles are acceptable. The nanoparticle scattering are uniformly distributed across the membrane surface thereby creating smooth surfaces which lower membrane surface energy and improve membrane wettability. Therefore, the random nature of nanoparticles scattering impacted surface energy driven separability of oil/water as revealed in Fig. 11 (a-f). It is also revealed from or flow rate are shown in Fig. 12 (a-d).

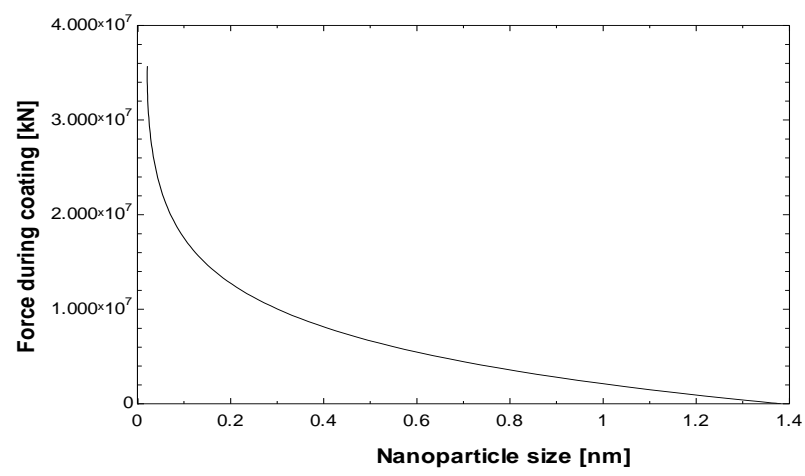

(a)

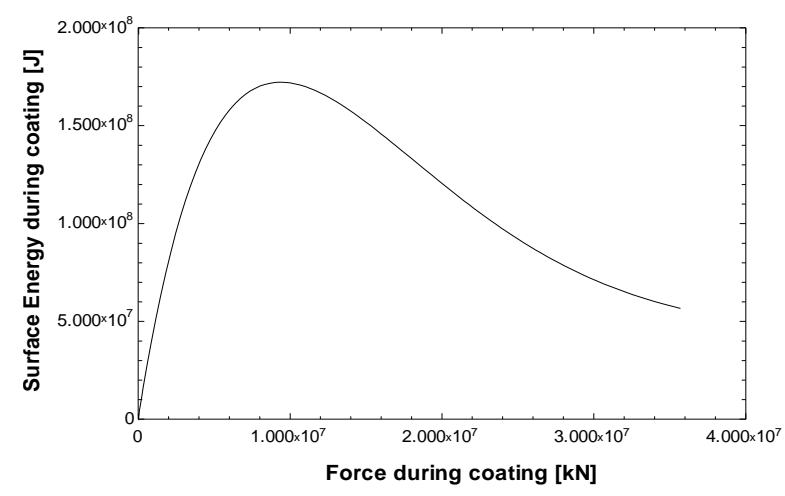

(c)
Fig. 11 (b) that decreases in aperture size and inter-separation distances on the membrane surfaces increases energy which negatively impacted membrane wettability.

It was also revealed from Fig.11 (b) that continuous decrease in membrane aperture size, nanoparticle scattering on the membrane surface did not always leads to increase in surface energy during wettability as there existed a critical nanoparticles scattering on the membrane surface which led to decrease in membrane surface energy which increases membrane wettability or flow rate. This also revealed the effect of surface roughness and smoothness of nanoparticles scattering on wettability during nanoparticle coating. Rough scattering of nanoparticles on the aperture led to higher surface energy that lower membrane wettability and smooth scattering of nanoparticles on the aperture led to lower surface energy which increases membrane wettability as shown in Fig. 11 (d). It is also revealed from Fig. 11 (a) that, change in membrane pressure (force) during nanoparticle coating leads to increase in membrane surface energy since more rough surfaces were created, which negatively affect membrane wettability and also the purity of the separated oil and water. The impacts of membrane force during coating on wettability

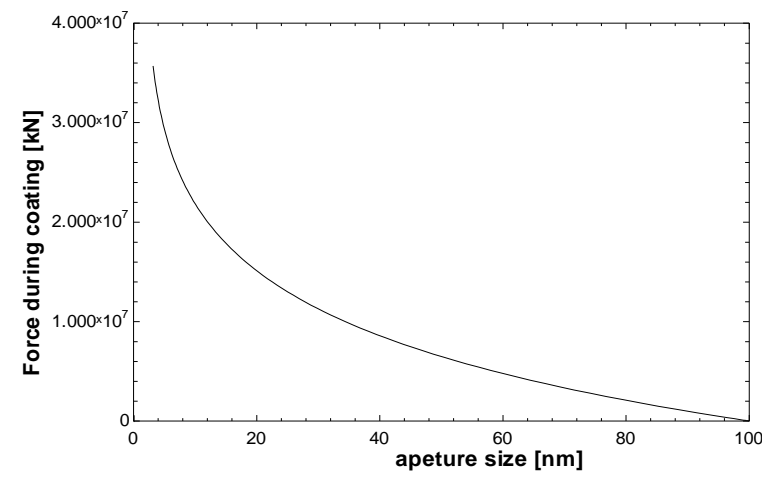

(b)

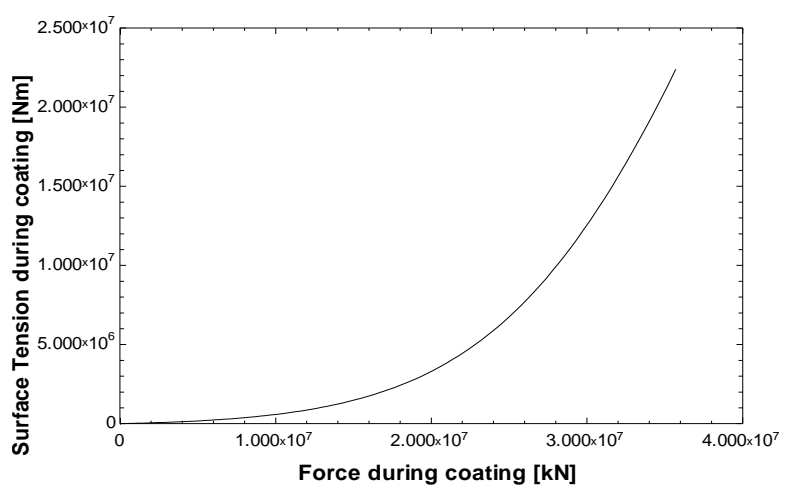

(d)

Figure 12. (a) Force during membrane coating $[\mathrm{kN}]$ against Nanoparticle sizes [nm](b) Force during membrane coating [kN] against aperture sizes [nm] (c) Surface Energy [J] against Force during membrane coating [kN](d) surface tension [Nm] against Force during membrane coating $[\mathrm{kN}]$ 
Figure 12 (a) revealed the relationship between membrane force during coating, nanoparticles sizes, aperture sizes, surface energy and surface tension during wettability. It is shown from Fig. 12 (a-b) that decrease in nanoparticle sizes and aperture sizes leads to increase in force during coating. The results in Fig. 12 (c) revealed that decrease in force during coating leads to increases in membrane energy to an optimal energy where membrane energy starts decreasing during the coating process. The results in Fig. 12 (b) revealed that increase in force during membrane coating leads to increase in surface tension.
The current research findings have revealed results, which other researchers have not reported on nanoparticles scattering during membrane coating. Optimal membrane inter-separation distances and aperture sizes during nanoparticle coating have been revealed. The derived theoretical model results of nanoparticles scattering were experimentally validated wettability test. There was a need to performed the real wettability experiments for the purpose of validation of the theoretical obtained results and SEM, EDS and statistical analysis in the current thesis.

\section{4 . Experimental setup of the new membrane technology used in oil/water separation}

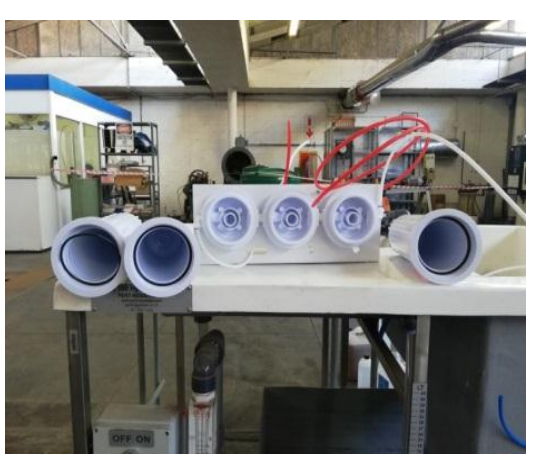

(a)

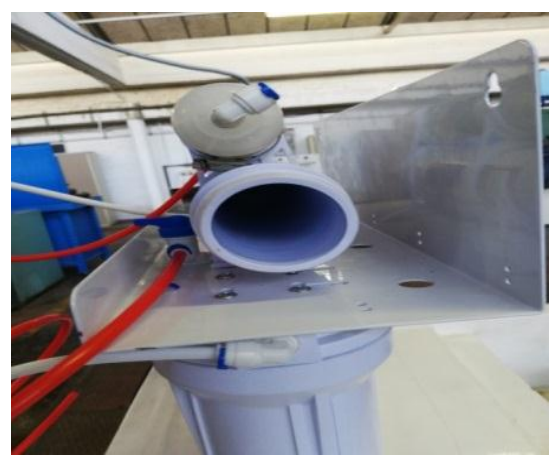

(b)

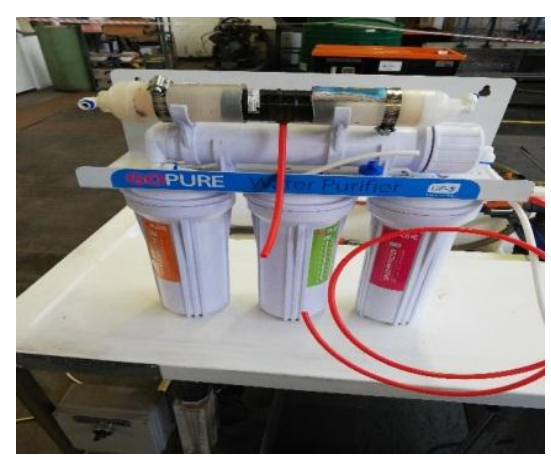

(c)

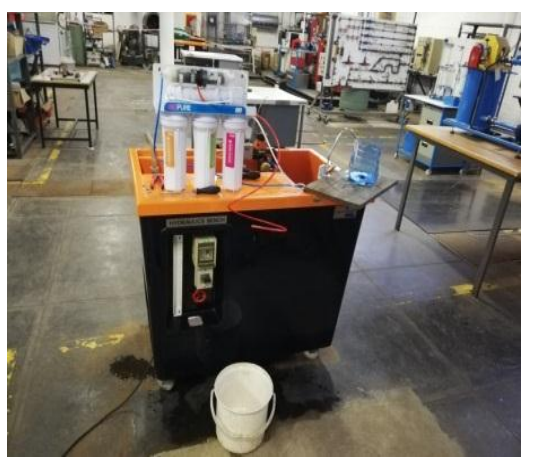

(d)

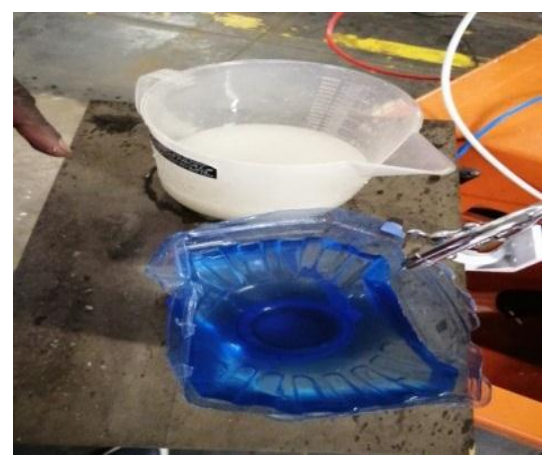

(e)

Figure 13 (a-b) membrane installations in progress (c) installation of proposed nanostructured membrane (d) experimental setup of Nanostructure Membrane technology used in oil/water separation (e) separated water from contaminated oil/water after experimentation.

\subsection{Experimentation of oil/water separation to validate the newly design nanostructured membrane}

A centrifugal pump was used to pump oil/water mixture from the storage tank through the nanostructured membrane to the final point were only pure water was collected as shown in Fig. 13 (e). The gauge pressure was at $180 \mathrm{kPa}$ during oil/water separation and the rate of flow of water during pump operation was 10 litres/s. The experiment was performed at room temperature and at a steady pressure supply by the centrifugal pump. Glass $1^{\text {st }} \mathrm{LP}, 2^{\text {nd }} \mathrm{LP}, 3^{\text {rd }} \mathrm{LP}, 1^{\text {st }} \mathrm{HP}, 2^{\text {nd }} \mathrm{HP}$ and $3^{\text {rd }}$ HP was tested for validation of wettability surface. The different obtained results were sent for analysis chemical analysis at AMBIO laboratory to detect the level the impurities of oil that was not filtered by the membrane technology. This was also done to adhere to National Engineering practice and regulation given by the South Africa Engineering Council for pollution control and environmental safety.

\subsection{Oil and Grease Analysis Using US EPA Method 1664B with the SPE-DEX 1000 Oil and Grease System}

The extraction of oil (Petrol) from the purify water after experiments was done using US EPA method 1664B with the SPE-DEX 1000 oil system using the four main step (1) Prewet/Conditioning solvent: when the disc is Pre-wet with a solvent to make it ready for the sample. Step 2, Processing of sample: when the sample from its original sample bottle is process through the SPE-Disk. Step 3. Solvent rinse of sample bottle: a solvent is used to rinsing the bottle and to ensure the 
International Journal of Engineering Research and Technology. ISSN 0974-3154, Volume 13, Number 5 (2020), pp. $842-866$

(C) International Research Publication House. https://dx.doi.org/10.37624/IJERT/13.5.2020.842-866

entire sample is extracted. Step 4: Extraction of the SPE Disk: the disk is extracted and analysed in a small volume of solvent rather than in a large volume of water were they started. The pan is removed from the heat source (compressor). Any oil or grease will be evidence by a white spot on the pan when pure water must have been evaporated during the heating process. Then the pan was weight the pan and subtracts the initial anti pan value from the full pan value to get your gravimetric value. The following obtained results for glass LP and HP rounds of coating were obtained as shown in Fig.14.

\begin{tabular}{|l|l|l|l|}
\hline \multirow{2}{*}{$\begin{array}{c}\text { Report } \\
\text { Ltd }\end{array}$} & $\begin{array}{l}\text { AMBIO Environmental Management (Pty) } \\
\text { Issue Date: } \\
2017 / 07 / 18\end{array}$ & Revision \#:6 \\
\hline Document identification: Form Report & $\begin{array}{l}\text { Revision Date: } \\
2017 / 07 / 17\end{array}$ \\
\hline
\end{tabular}

Results of analysis: Chemistry Analysis

Customer: Mechanical Department

Address:

Vaal University of Technology

Email:

baonhe_soberocketmail.com

Report number

001

\begin{tabular}{|l|l|}
\hline Samples Received: & $2019 / 09 / 16$ \\
\hline Date of Analysis: & $2019 / 09 / 19$ \\
\hline Sample Container: & $1000 \mathrm{ml}$ Glass bottle \\
\hline Sample type: & Treated oil contaminated water \\
\hline
\end{tabular}

Results: Table 1

\begin{tabular}{|l|l|l|l|l|l|}
\hline \multicolumn{1}{|c|}{ Determinant } & unit & Glass HP1 & Glass HP2 & Glass HP3 & Glass LP1 \\
\hline Oil and grease & $\mathrm{mg} / 1$ & 1.35 & 0.81 & 10.94 & 6.35 \\
\hline
\end{tabular}

Results Table 2

\begin{tabular}{|c|l|l|l|l|}
\hline Determinant & Unit & Glass LP2 & Glass LP3 & Reporting Limit \\
\hline Oil and grease & $\mathrm{mg} / 1$ & 0.09 & 0.64 & 2000 \\
\hline
\end{tabular}

$<1$ indicates that the determinant was not detected

- AMBIO will perform correct analyses, AMBIO shall not be liable for damages arising from loss or injury caused directly or indirectly by or contributed by or arising from any inaccuracy of the analysis or the interpretation thereof.

- Results relate only to items tested by the laboratory.

- The Laboratory does not give any opinions and interpretations as that falls outside the scope of accreditation.

Figure 14 Wettability test for oil/water separation on glass LP and HP rounds.

Table 1 and table 2 of Fig. 14 revealed the final laboratory results after oil and grease Analysis were performed. The determinant was oil in the contaminated water and oil that were filtered through the designed nanostructured membrane.
The wettability of six membranes HP and LP were tested for validation purpose. The obtained values greater 1 revealed that oil was not detected in the filtered water. The obtained values less than 1 indicated that oil was detected in the filtered 
water after wettability test. Therefore these obtained results can be correlated with the different results of HP and LP coating rounds. It is observed as shown in Fig.1 that glass HP 3 show more efficient wettability when compared with all the glass coating rounds. It was important to compare the SEM images for validation of their surface properties. It was observed that $3^{\text {rd }} \mathrm{HP}$ coating rounds have little or no clusters on its surface when compared with the other wetting rounds. Therefore it is clear that the presence of clutters is an indication of poor wettability. Glass $2^{\text {nd }}$ round LP coating revealed the membrane surface with poor wettability since few oil molecules were observed in the separated water. The reason for poor oil/water separation process as shown in $2^{\text {nd }}$ $\mathrm{HP}, 2^{\text {nd }} \mathrm{L}$ and $3^{\text {rd }} \mathrm{LP}$ is due to high surface roughness and more clusters being observed. More clusters were observed in these membrane surface and clusters are reported to increases surface roughness. These surfaces are also reported to have large nanoparticle inter-separation distances. Their orientation of nanoparticles, morphology of nanoparticle, spatial distribution of nanoparticle and nanoparticle size are affected by clusters.

\section{CONCLUSION AND RECOMMEDATION}

The current study was aimed at studying the stochastic effect of nanoparticles inter-separation distances and their impact on wettability during oil/water separation. To achieve this objective a new membrane surface was created and the interseparation distances were theoretically modelled and validated experimentally. It was revealed that there is an optimal nanoparticles inter-separation distance which gave optimal membrane wettability after $3^{\text {rd }}$ HP round of coating. Different orientation of nanoparticles, size, shape, spatial distribution and morphology were also observed to impact membrane wettability. Clusters were also observed on the membrane and more clusters were observed in LP coating when compared with HP coating. These clusters greatly impacted membrane wettability negatively. Good correlation was observed from the SEM images, EDS and Descriptive statistics of the amount of elements in the surface layer formed after different coating rounds. There was a need to do a theoretical simulation so as to do a proper correlation of experimental observed variable and theoretical observed variable.

It was shown that decrease in nanoparticle sizes during nanoparticle scattering which affects wettability and leads to increase in membrane surface energy i.e increase hydrophobicity during membrane coating. It is also revealed that the continuous decrease of the nanoparticles on the membrane surface during coating did not lead to increase in energy in the membrane surface during wettability since the membrane surface became smoother or less rough due to varying nanoparticle scattering on the membrane surface which impacted wettability. The theoretical results showed a smooth transition from higher surface energy due to proper membrane inter-separation distances which lower surface energy. It was revealed that rough membrane surfaces created higher surface energy and their inter-separation distances were higher with negative impact on membrane wettability or flow rate. Therefore the theoretical obtained result revealed that the effect of roughness to smoothness due to change in membrane inter-separation distances was a consequence of continuous coating from $1^{\text {st }}$ to $3^{\text {th }}$ coating. Though membrane wettability were observed for smoother membrane surface the presence of cluster during LP and HP coating is a serious problem which need further investigation.

\section{ACKNOWLEDGEMENT}

Theresearch is supported by the Vaal University of Technology South Africa and the National Research Foundation (NRF). The relevant experiments and simulations were performed using Engineering Equation Solver (EES) and experimental data were captured at the microscopy unit in SEFAKO MENDUNSA HEALTH SCIENCE UNIVERSITY PRETORIA SOUTH AFRICA.

\section{Data availability}

The authors have given simulated data and data obtained during TEM, SEM and energy dispersion spectroscopy as requested by the editor. Other data could not be disclosed for confidentiality. See the appendix section of this paper.

\section{Conflicts of Interest}

The authors declare that they have no conflicts of interest in the manuscripts between authors and involved institutions.

\section{REFERENCE}

[1] Ye Q., Shen, B, Tiedje, O., Domnick, J., Investigations of spray painting processes using an airless spray gun. ILASS - Europe 2011, 24th European Conference on Liquid Atomization and Spray Systems, Estoril, Portugal, September 2011

[2] M. W. Plesniak, P. E. Sojka, A. K. Singh: Transfer Efficiency for Airless Painting Systems, JCT Research, Vol. 1, No. 2, April 2004

[3] Q. Ye, J. Domnick, A. Scheibe: Numerical simulation of spray painting in the automotive industry, Proceedings of the 1st European Automotive CFD Conference Bingen, Germany, June 2003

[4] J. Domnick, A. Scheibe, Q. Ye: The simulation of the electrostatic spray painting process with high-speed rotary bell atomizers. Part I: Direct charging, Part. Part. Syst. Charact. 22 (2005) 141-150

[5] J. Domnick, A. Scheibe, Q. Ye: The simulation of the electrostatic spray painting process with high-speed rotary bell atomizers. Part II: External Charging. Part. Part.Syst. Charact. 23(2006) 408-416

[6] Q.Ye, J. Domnick, E. Khalifa : Simulation of the spray coating process using a pneumatic atomizer. ILASS- 
Europe, September 2002, Zaragoza

[7] Mohammad Rezaei, Wolfgang Samhaber (2016). Wetting Behaviour of Super hydrophobic Membranes Coated with Nanoparticles in Membrane Distillation. Johannes Kepler University Linz, Process Engineering Institute, Welser Strasse 42, 4060 Leonding, Austria (2016).

[8] Huili Peng, Hao Wang, Jianning Wu, Guihua Meng, Yixi Wang, Yulin Shi, Zhiyong Liu, and Xuhong Guo (2016). Preparation of Superhydrophobic Magnetic Cellulose Sponge for Removing Oil from Water. DOI:10.1021/acs.iecr.5b03862 Ind. Eng. Chem. 55, 832-838.

[9] Wang, B.; Liang, W.; Guo, Z.; Liu, W (2015). Biomimetic superlyophobic and super-lyophilic materials applied for oil/water separation: a new strategy beyond nature. Chem. Soc. Rev. 44 (1), 336-361.

[10] Cheng, Z.; Wang, J.; Lai, H.; Du, Y.; Hou, R.; Li, C. (2015). Zhang, N.; Sun, K. pH-Controllable On-Demand Oil/Water Separation on the Switchable Superhydrophobic/Superhydrophilic and Underwater Low-Adhesive Superoleophobic Copper Mesh Film. Langmuir, 31 (4), 1393-1399.

[11] Ke, Q.; Jin, Y.; Jiang, P.; Yu, J. (2014). Oil/Water Separation Performances of Superhydrophobic and Superoleophilic Sponges. Langmuir. 30 (44), 13137-13142.

[12] Jiang, F.; Hsieh, Y.-L. (2014). Amphiphilic superabsorbent cellulose nanofibril aerogels. J. Mater. Chem. A, 2 (18), 6337-6342.

[13] Duan, C.; Zhu, T.; Guo, J.; Wang, Z.; Liu, X.; Wang, H.; $\mathrm{Xu}, \mathrm{X}$; Jin, Y.; Zhao, N.; Xu, J. (2015). Smart Enrichment and Facile Separation of Oil from Emulsions and Mixtures by Superhydrophobic/Superoleophilic Particles. ACS Appl. Mater. Interfaces. 7 (19), 10475-10481.

[14] Wu, L.; Li, L.; Li, B.; Zhang, J.; Wang, A. (2015). Magnetic, Durable, and Superhydrophobic Polyurethane@Fe3O4@SiO2@Fluoropolymer Sponges for Selective Oil Absorption and Oil/Water Separation. ACS Appl. Mater. Interfaces, 7 (8), 4936-4946.

[15] Si, Y.; Fu, Q.; Wang, X.; Zhu, J.; Yu, J.; Sun, G.; Ding, B. (2015). Superelastic and Superhydrophobic Nanofiber-Assembled Cellular Aerogels for Effective Separation of Oil/Water Emulsions. ACS Nano. 9, 3791.

[16] Zhou, X.; Zhang, Z.; Xu, X.; Men, X.; Zhu, X. (2013). Facile Fabrication of Superhydrophobic Sponge with Selective Absorption and Collection of Oil from Water. Ind. Eng. Chem. 52 (27), 9411-9416.
[17] Zhu, Q.; Chu, Y.; Wang, Z.; Chen, N.; Lin, L.; Liu, F.; Pan, Q. (2013). Robust superhydrophobic polyurethane sponge as a highly reusable oil-absorption material. J. Mater. Chem. A, 1 (17), 5386-5393. (10) Pham, V. H.; Dickerson, J. H. Superhydrophobic Silanized Melamine Sponges as High Efficiency Oil Absorbent Materials. ACS Appl. Mater. Interfaces 2014, 6 (16), 14181-14188.

[18] Zhou, X.; Zhang, Z.; Xu, X.; Men, X.; Zhu, X. (2013). Facile Fabrication of Superhydrophobic Sponge with Selective Absorption and Collection of Oil from Water. Ind. Eng. Chem. 52 (27), 9411-9416.

[19] Yang, X.; Cranston, E. D. (2014). Chemically CrossLinked Cellulose Nanocrystal Aerogels with Shape Recovery and Superabsorbent Properties. Chem. Mater. 26 (20), 6016-6025.

[20] Kong, L.; Wang, Q.; Xiong, S.; Wang, Y. (2014). Turning Low-Cost Filter Papers to Highly Efficient Membranes for Oil/Water Separation by Atomic-LayerDeposition-Enabled Hydrophobization. Ind. Eng. Chem. 53 (42), 16516-16522.

[21] Nguyen, S. T.; Feng, J.; Le, N. T.; Le, A. T. T.; Hoang, N.; Tan, V. B. C.; Duong, H. M. (2013). Cellulose Aerogel from Paper Waste for Crude Oil Spill Cleaning. Ind. Eng. Chem. 52 (51), 18386-18391.

[22] Gert H. ten Brink, Nolan Foley, Darin Zwaan, Bart J. Kooi and George Palasantzas, 2015. Roughness controlled superhydrophobicity on single nanometer length scale with metal nanoparticles. Cite this: RSC Adv., 2015, 5, 28696.

[23] Young T, Philos (1805). Trans. R. Soc. Lond. 95, 65

[24] Glen, R B., Austin, W. Boesh \& Matthew, J. L. (2005). The effects of flow rate on membrane capacity: Development and application of adsorptive membrane fouling models. Journal of Membrane Science 279 (2006) 625-634.

[25] Binshan, J. \& Tailiang, F. (2009). Experimental study and mathematical model of nanoparticle transport in porous media. Powder technology, Vol.192.

[26] Sob. P.B, Tengen, T.B, Alugongo, A. A. 2016. Modeling strain rate sensitive nanomaterials mechanical properties: the effects of varying definitions. A dissertation submitted in fulfilment of the requirements for the degree Magister Technologiae in Mechanical Engineering In the Faculty of Engineering \& Technology Vaal University of Technology. 
International Journal of Engineering Research and Technology. ISSN 0974-3154, Volume 13, Number 5 (2020), pp. $842-866$

(C) International Research Publication House. https://dx.doi.org/10.37624/IJERT/13.5.2020.842-866

\section{APPENDIX}

"surface energy and flow rate models"

integral $\left(\left(\left(v * t \_3\right) /\left(22 / 7 * r^{\wedge} 2 * t \_2\right)-S \_1\right)\right.$, time, 0,1000$)=d \_s " c h a n g e$ of membrane pore/channel due to orientation"

$\mathrm{v}=200$

$\mathrm{t} \_3=1$

t_2=3

S_1=0.03 "exterior length of membrane pore/channel in $\mathrm{mm} "$

integral(V_0/T_TIME,time,0,1000)=Q_experimental"experimental flow rate"

V_0=20 "litres of water collected"

T_TIME=60 "time to collect the volume of water"

d_p=integral $\left(1 / 2 * 1000 *\left(A \_p / A \_z * V \_1\right)^{\wedge} 2\right.$, time, 0,1000$)$ -

integral $\left(1 / 2 * 1000 *\left(V_{-} 1\right)^{\wedge} 2\right.$,time, 0,1000$)$ "pressure difference in membrane"

A_p $=8$

A_ $z=4$

F_total=F_viscosity+F_upward-F_down+F_water+F_angle"total membrane forces"

F_upward=integral(W_weight,time,0,1000) "on the membrane surface"

W_weight=2000 "specific weight of water"

F_viscosity=integral((0.000720/1000),time,0,1000) "due to flow of water"

F_down=integral $(100$, time, 0,1000$)$ "force down the membrane"

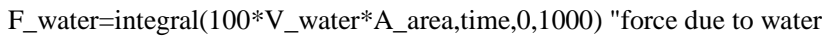
pressure"

V_water=100 "velocity of water"

A_area $=3$ "area of membrane pore"

F_angle=integral $\left(100 * 1 * 0.174 * A \_\right.$angle,time, 0,1000$)$ "force due to water angle"

A_angle $=90$
Energy=F_total*r_apeturesize $/ 2$

Q_flowratetheoretical=(d_p*A_r $) /\left(R \_f * v \_s\right)$ "theoretical flow rate"

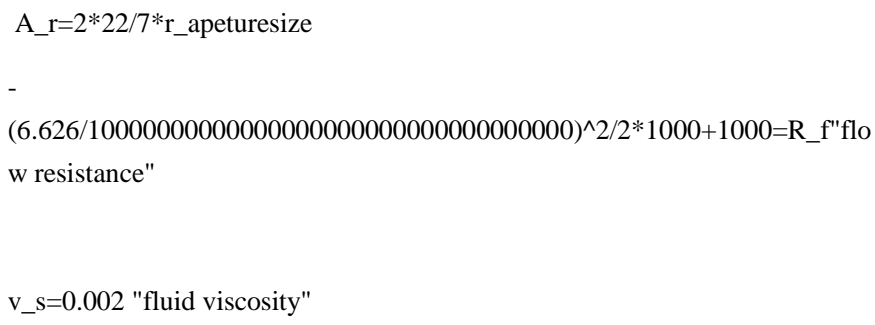

v_s=0.002 "fluid viscosity"

r_apeturesize $=r-(10) /\left(\mathrm{N} \_\right.$particle +1000000$) * Y "$ nanoparticles size and channel"

N_particle $=(2 *$ r_apeturesize $* Y-Y) / Y^{\wedge} 2 "$ maximum number of grain to be coated to optimal wettability"

change_surfaceenergy $=\left(\mathrm{F} \_\right.$Total*d_s $) / \mathrm{d} \_\mathrm{A}$

d_A $=2$

Surface_Tension $=F \_T o t a l /(2 * 22 / 7 *$ r_apeturesize $*$ S_porelength $)$

S_porelength $=0.08$

Change_Temperaturetension $=$ integral $\left(\left(\right.\right.$ Surface_Tension/ $\left.(1000) / 1^{\wedge} 11 / 9\right) * 647$, time, 0,1000$)$

Change_Temperatureenergy=integral((Energy/(1000)/1^11/9)*647,time,0,10 00)

E_electricfield=integral(Q_e*E_f,time,0,1000)

Q_e=9.11/100000000 "electric charge electron"

E_f $=1$ "static electric field"

d_gravitation=integral $\left(d \_p /\left(1000 * h \_a\right), t i m e, 0,1000\right)$

h_a $=5$

Surface_Energy $=F \_T o t a l * r \_a p e t u r e s i z e / 2$

shear_force=-changein_channelpressure*S_porelength/d_L 
International Journal of Engineering Research and Technology. ISSN 0974-3154, Volume 13, Number 5 (2020), pp. $842-866$

(C) International Research Publication House. https://dx.doi.org/10.37624/IJERT/13.5.2020.842-866

changein_channelpressure $=\left(8 * L^{*}\right.$ velocity*Average_velocity $) /(1000 *$ viscosit $\mathrm{y} * \mathrm{~S} \_$porelength*(R_channel/2)^2) "change in membrane channel pressure $\mathrm{p} 1-\mathrm{p} 2 "$

$\mathrm{L}=0.03$

d_L=1

velocity=-

$\left(\left(\mathrm{S} \_ \text {porelength*changein_channelpressure }\right) /(\text { viscosity*d_L })\right)^{*}\left(\mathrm{R} \_\right.$channel-

r_apeturesize)

viscosity $=(1000 *$ velocity*r_apeturesize $) /(1800)$

R_channel $=8 / 1000$

Average_velocity=-

$\left(\left(\mathrm{S} \_ \text {porelength*changein_channelpressure }\right) /(\text { viscosity*d_L })\right)^{*}\left(22 / 7 * \mathrm{R} \_\right.$chann

el-r_apeturesize)/2

Maxi_velocity=-

$\left(\left(\mathrm{S} \_ \text {porelength*changein_channelpressure }\right) /(\text { viscosity*d_L })\right)^{*} \mathrm{R} \_$channel-

r_apeturesize

Flowratein_channel=integral(velocity $* 2 * 22 / 7 *$ r_apeturesize,time,0,1000)

Flowrate_parallelchannel $=\left(2 * 22 / 7 * \mathrm{~S} \_\right.$porelength $) /$viscosity*integral(d_p*r_a peturesize^4/16-r_apeturesize ${ }^{\wedge} 3 / 3$, time, 0,1000 )

velocitymaximum_channel $=\left(\mathrm{S} \_\right.$porelength $/ 2 *$ viscosity $) *$ integral $\left(\mathrm{d} \_\mathrm{p} * \mathrm{r} \_\right.$apetu resize^2/4-r_apeturesize,time,0,1000)

drag_profile=pressureofdrag+frictionofdrag

pressureofdrag $=(1 / 2) *\left(2 * 1000 / 1000 *\right.$ viscosity $* 2 * 22 / 7 * \mathrm{r} \_$apeturesize $* \mathrm{~S} \_$porel ength)*integral(cosA*S_porelength, time,0,1000)

$\cos \mathrm{A}=30$

frictionofdrag=shear_force* $1 / 2 *(2 * \mathrm{~L} / 1000 * 2 * 22 / 7 * \mathrm{r}$ _apeturesize $*$ S_porelen gth*velocity^2)*integral(sinA*S_porelength,time,0,1000) $\sin A=30$

Interseparationdistance $=\left((4 / 3) *(22 / 7) *\left(r \_\right.\right.$apeturesize $\left.{ }^{\wedge} 2\right) * \operatorname{integral}(1 /(4 / 3 * 22 / 7$ $* 1 * r$ apeturesize $\left.{ }^{\wedge} 3\right)^{*}\left(1+(22 / 7) *(3 / 4) *(22 / 7) * r\right.$ _apeturesize $\left.{ }^{\wedge} 3\right) * r$ _apeturesize,t ime,0,1000))/10000000 "membrane coating inter-separated distances during coating process"

Force_z $=2 * 1000 *$ velocity^ $2 * \cos \mathrm{A} \quad$ "Force on the membrane along the $\mathrm{z}$ plane during coating process"

F_total_during_coating=F_viscosity+F_upward-

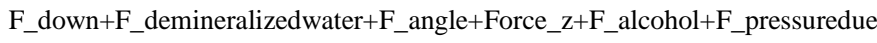
tospraygun-F_frictionduetoreaction "total membrane forces during the coating process"

F_demineralizedwater=integral $\left(100 * \mathrm{~V} \_\right.$water*A_area,time, 0,1000$)$ "force due to demineralised water pressure"

F_alcohol=integral((0.000720/1.031),time,0,1000) "due to flow of alcohol"

F_pressureduetospraygun=integral(W_weight/A_r,time,0,1000) "on the membrane surface"

F_frictionduetoreaction=integral $(0.8 * 9.81 * 100$, time, 0,1000$)$

Surface_Energy_coating=F_Total_during_coating*r_apeturesize/2

Surface_Tensionduringcoating=F_Total_during_coating/(2*22/7*r_apeturesi ze*S_porelength)

\$Integral

Q_experimental,Q_flowratetheoretical,d_p,S_surfaceenergychange,S_particle energychange,F_total,S_surfacetensionchange,T_temperaturechange,E_electr icfield,d_gravitation,Energy,

r_apeturesize,N_particle,change_surfaceenergy,Surface_Tension,Surface_En ergypore,F_angle,Change_Temperaturetension,Change_Temperatureenergy,E _electricfield,d_gravitation,Surface_Energy,shear_force,viscosity,Maxi_veloc ity,Average_velocity,changein_channelpressure,viscosity,Flowratein_channel ,Flowrate_parallelchannel,velocitymaximum_channel,drag_profile,Intersepar ationdistance,

Force_z,F_total_during_coating,Surface_Energy_coating,F_total_during_coat ing,Surface_Tensionduringcoating 
International Journal of Engineering Research and Technology. ISSN 0974-3154, Volume 13, Number 5 (2020), pp. $842-866$ (C) International Research Publication House. https://dx.doi.org/10.37624/IJERT/13.5.2020.842-866
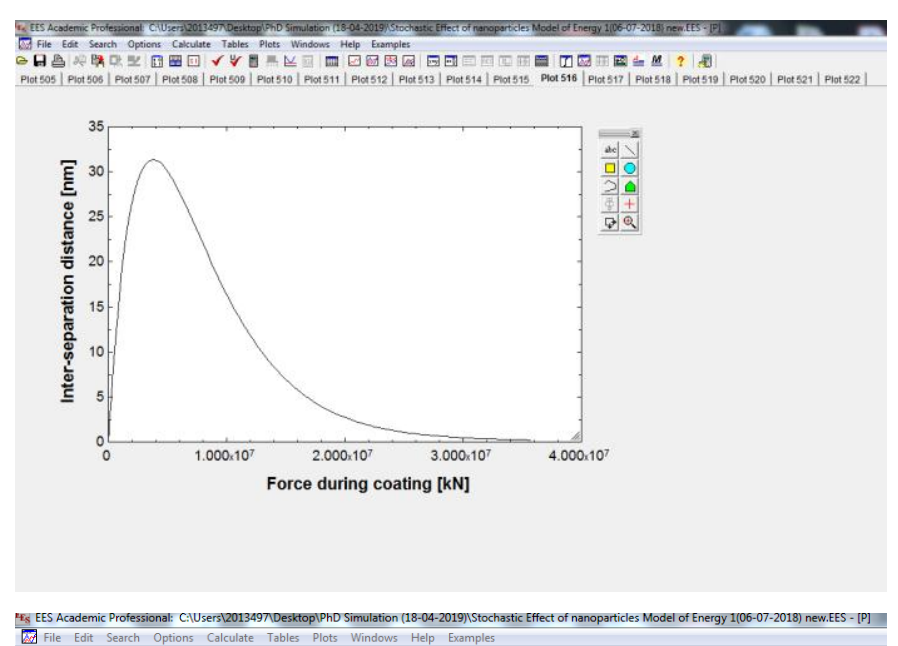

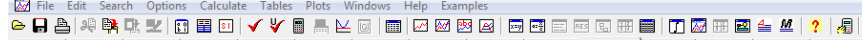
Plot 505 | Plot 506 | Plot507| Plot 508 | Plot 509 | Plot 510 | Plot511| Plot 512 | Plot 513 | Plot 514 . Plot 515 | Plot 516 | Plot 517 | Plot 518 | Plot 519 | F

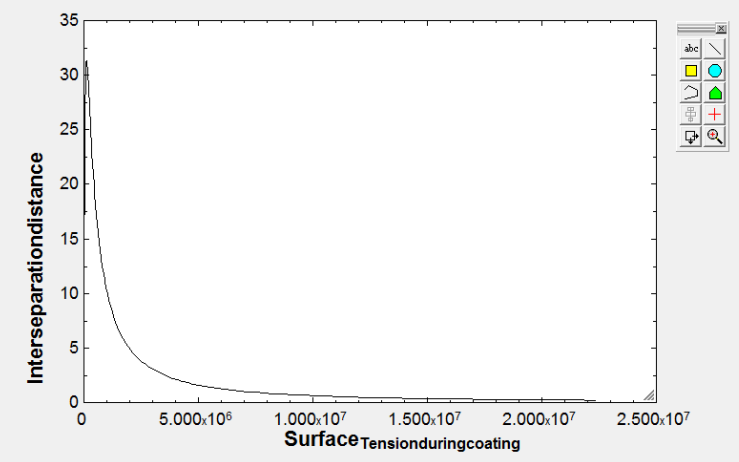

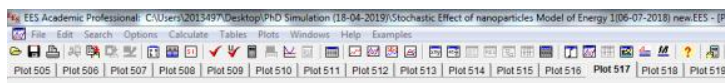

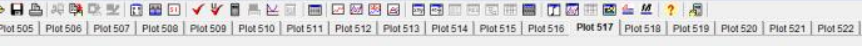

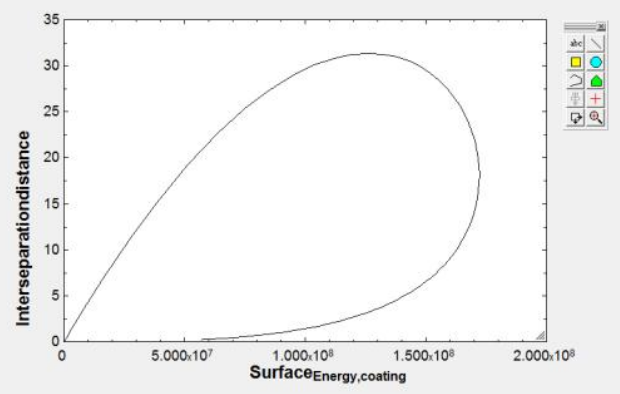

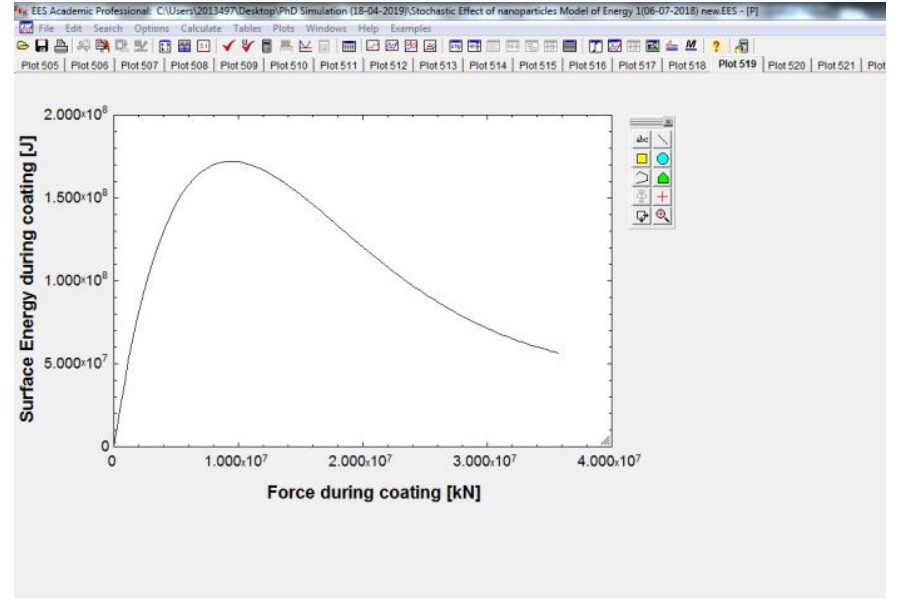

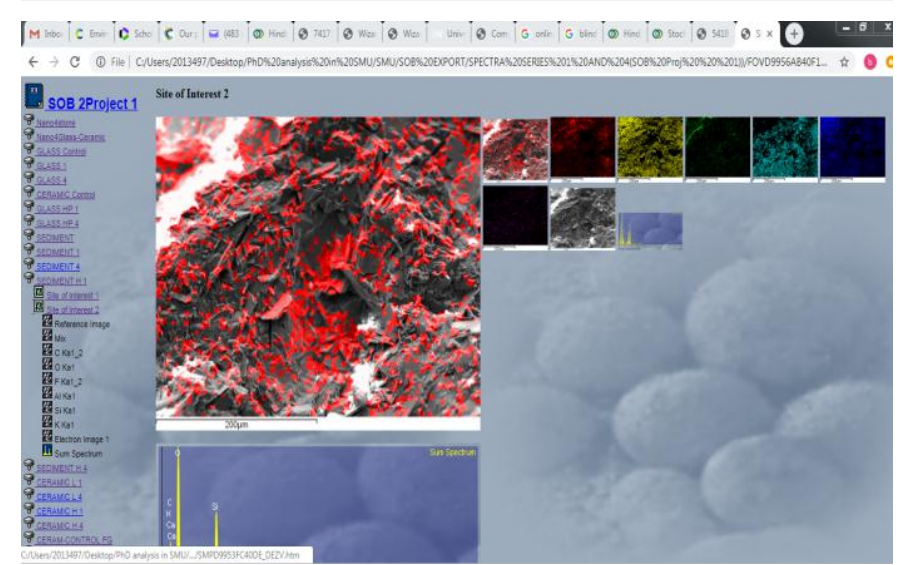

